\title{
Improving Photosynthetic Responses during Recovery from Heat Treatments with Brassinosteroid and Calcium Chloride in Indian Bread Wheat Cultivars
}

\author{
Suboot Hairat, Paramjit Khurana \\ Department of Plant Molecular Biology, University of Delhi, South Campus, New Delhi, India \\ Email: param@genomeindia.org, hsuboot@yahoo.com
}

Received 21 April 2015; accepted 26 July 2015; published 29 July 2015

Copyright (C) 2015 by authors and Scientific Research Publishing Inc.

This work is licensed under the Creative Commons Attribution International License (CC BY). http://creativecommons.org/licenses/by/4.0/

(c) (i) Open Access

\begin{abstract}
Climate change is expected to unleash severe and frequent heat waves in future, adversely affecting crop productivity. The aim of this study was to examine the effect of two separate episodes of heat stress, mimicking heat wave conditions on the physiology of four Indian bread wheat cultivars and to study the ameliorating effects of epibrassinolide (BR) and calcium chloride on the recovery of these cultivars. The two thermo-tolerant cultivars $C 306$ and $K 7903$ suffered less inhibition of photosystem II efficiency as compared to the two thermo-susceptible cultivars HD2329 and $P B W 343$. Application of $B R$ and calcium chloride resulted in faster recovery in all the four cultivars. Measurement of the minimum fluorescence (Fo) versus temperature curves revealed a higher inflection temperature of Fo (Ti) for the two tolerant cultivars as compared to the susceptible cultivars, emphasizing greater thermo stability of the photosynthetic apparatus. The two thermotolerant cultivars showed higher photochemistry ( $\phi$ PSII) relative to the two susceptible cultivars. An increase in the steady state fluorescence was observed in both the susceptible cultivars as compared to the tolerant cultivars. Expression analysis revealed faster recovery of the transcripts involved in photosynthesis in tolerant cultivars as compared to susceptible cultivars. Exogenous application of the ameliorating compounds resulted in faster recovery of transcripts in all the cultivars. The result suggested that under severe stress conditions tolerant cultivars showed faster recovery and a better thermo-stability of its photosynthetic apparatus as compared to susceptible cultivars and application of epibrassinolide and calcium chloride could ameliorate the damaging effect of severe temperature stress to a considerable level in all the four cultivars under study.
\end{abstract}

\section{Keywords}

Brassinosteroid, Calcium Chloride, Electron Transport Rate, Membrane Injury Index, 


\section{Non Photochemical Quenching, Photosynthetic Efficiency}

\section{Introduction}

Previous century has seen an increase of $0.74^{\circ} \mathrm{C}$ in global mean temperature which currently continuing to increase at $\sim 0.1^{\circ} \mathrm{C}$ per decade [1]. Global mean temperature increase will be associated with extreme heat events including severe heat waves along with hot days with more severity and frequencies over most land areas [1] [2]. Few studies have examined the responses of crop plants, to heat waves [3]-[6]. The highly susceptible state of photosynthesis will adversely affect photosynthesis at elevated temperature [7], photosynthetic capacity and photochemical efficiency [8]. Susceptibility of PSII and OEC to thermal stress has been shown [9].

Brassinosteroids (BR) are a group of steroids regulating plant growth and development by possible involvement in signaling pathways [10]-[12]. Important insights were made of the BR-insensitive transduction pathways due to discovery of BR-insensitive mutants in Arabidopsis (Arabidopsis thaliana), Pea (Pisum sativum), tomato (Solanum lycopersicum), and rice (Oryza sativa) leading to the isolation and characterization of BRI1 and its homolog [13]-[16]. Role of BR in imparting tolerance to different abiotic stresses including heat and cold stress, drought and salinity stress has been demonstrated [17]-[20]. Although the exact mechanism of the BR induced tolerance is not known, various reports have suggested increased expression of heat shock proteins via influence on some components of the translational machinery [21] [22].

Apart from its role as a nutrient, calcium also acts as a secondary messenger and is known to ameliorate water stress induced effects in higher plants [23]. Calcium is known to be involved in $\mathrm{H}_{2} \mathrm{O}_{2}$ perception, induction of antioxidant genes [24], cellular signaling processes [25], most notably by deciphering calcium signatures [26]. Influence of calcium in ameliorating the negative effects of different abiotic stresses is reported in a variety of plants [27]-[30]. A known calcium induced protective mechanism against abiotic stresses in plants is via the induction of anti-oxidative responses [28].

\section{Materials and Methods}

\subsection{Temperature Treatment}

For simulation of two consecutive heat wave effect on the four Indian bread wheat cultivars namely C306, K7903, HD2329 and PBW343, potted plants at anthesis stage were taken for this study. The schematic diagram of the experiment designed is presented in Figure 1. The experiment which was carried out over a span of five days with exposure to thermal stress of $43^{\circ} \mathrm{C}$ for $8 \mathrm{~h}$ with prior acclimatization at $37^{\circ} \mathrm{C}$ for $1 \mathrm{~h}$ was given on day one (D-1) and day three (D-3), day two (D-2), day four (D-4), day five (D-5) were the recovery period, when plants were kept at $22^{\circ} \mathrm{C}$ without stress. All analysis were carried out with the flag leaf. The 5 days of experiment starting from zero time were depicted as D-0, D-1, D-2, D-3, D-4 and D-5. For foliar application, a solution of BR $(0.05 \mu \mathrm{M})$ was mechanically sprayed on leaves for five days $12 \mathrm{~h}$ prior to exposure to high temperature stress during the span of experiment. Calcium chloride $(10 \mathrm{mM}, 1 \mathrm{~L})$ was added to pot $12 \mathrm{~h}$ prior to the start of experiment.

\subsection{Temperature Induction Response (TIR)}

For Temperature Induction Response (TIR), 20 seeds of uniform size were imbibed for 16 h in petri plates with approximately $15 \mathrm{ml}$ distilled water along with different chemicals including calcium chloride $\left(\mathrm{CaCl}_{2}\right)(1 \mathrm{mM}, 5$ $\mathrm{mM}$ and $10 \mathrm{mM})$, Brassinosteroid (BR) $(0.01 \mu \mathrm{M}, 0.05 \mu \mathrm{M}$ and $0.1 \mu \mathrm{M})$, salicylic acid (SA) $(100 \mu \mathrm{M}, 500 \mu \mathrm{M}$ and $1000 \mu \mathrm{M})$, abcissic acid (ABA) $(5 \mu \mathrm{M})$ and 1-aminocyclopropane-1-carboxylic acid (ACC) (100 $\mu \mathrm{M})$. Seeds showing germination were subjected to lethal temperature stress of $51^{\circ} \mathrm{C}$ for $3 \mathrm{~h}$ with prior induction at sublethal temperature of $37^{\circ} \mathrm{C}$ for $1.5 \mathrm{~h}$. Immediately after the treatment, seedlings were allowed to recover at $22^{\circ} \mathrm{C} \pm 1^{\circ} \mathrm{C}$. On the $10^{\text {th }}$ day, from the date of imbibition of seeds, the percentage survival of seeds were scored [31].

\subsection{Chlorophyll Fluorescence and Photosynthesis}

Chlorophyll fluorescence parameters were measured continually in situ from D-0 to D-5 with Licor 6400 
(a)

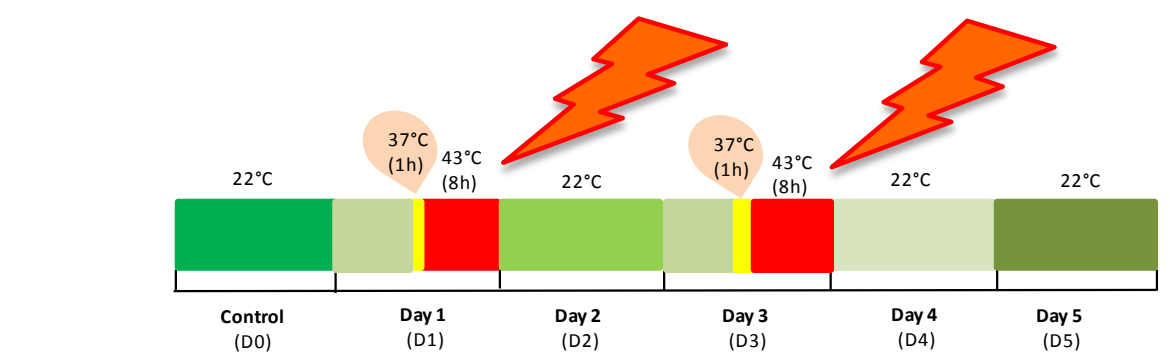

(b)

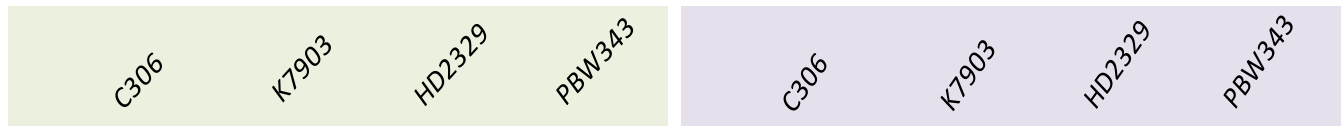
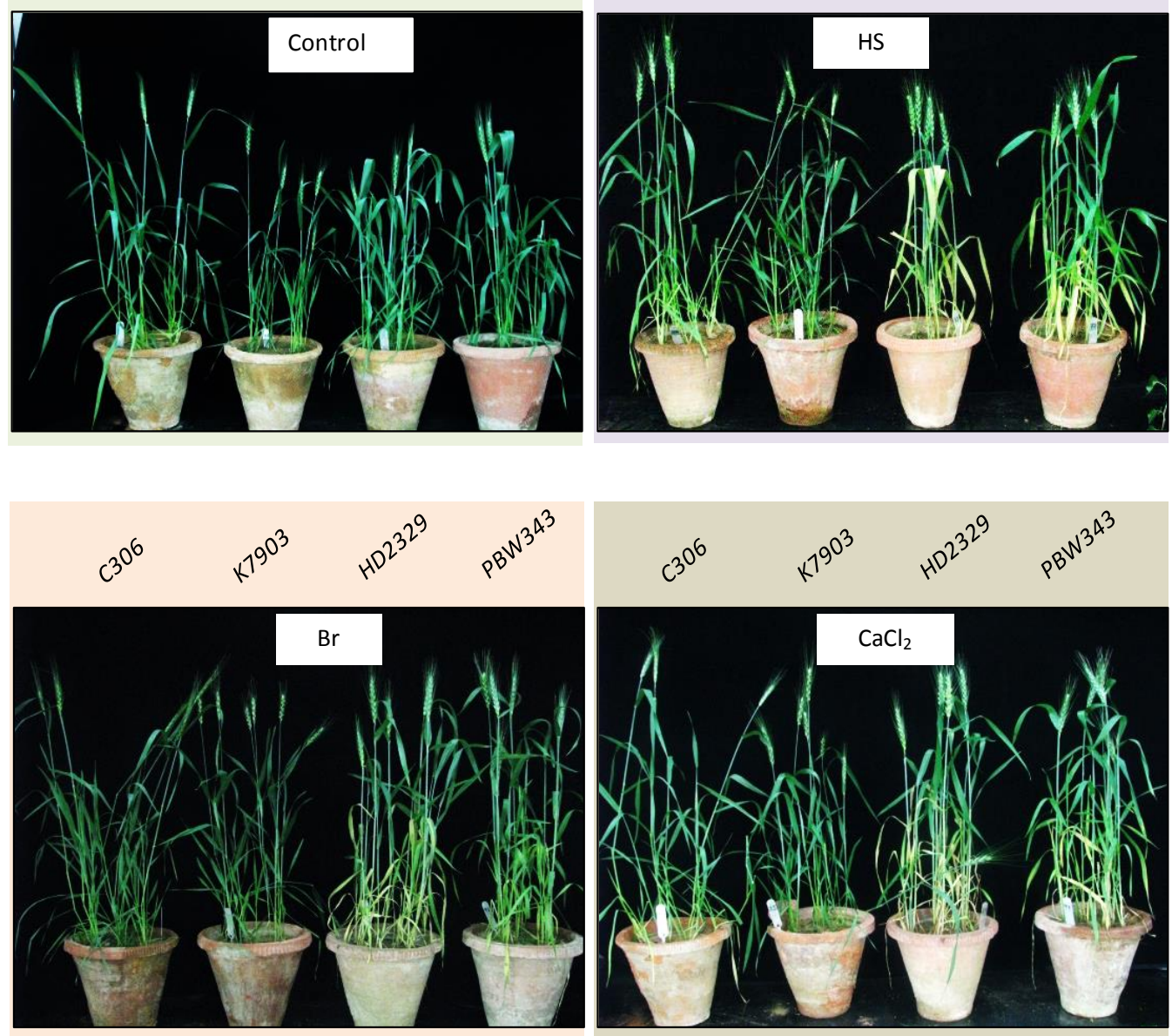

Figure 1. (a) Schematic representation of the experimental design spanning over a span of five days with temperature stress given on day 1 (D-1) and day 3 (D-3); (b) Influence of exogenously applied compounds including $\mathrm{CaCl}_{2}$ (Calcium chloride) $(10 \mathrm{~mm})$ and $\mathrm{Br}$ (Brassinosteroid) $(0.05 \mu \mathrm{M})$ followed by heat treatment in different wheat cultivars on Day 5.

(Portable Photosynthesis System, Li-Cor, Lincoln, NE, USA). For measuring Fm, dark adapted leaves were given a $0.8 \mathrm{~s}$ saturating pulse at $8000 \mu \mathrm{mol} \mathrm{m}{ }^{-2} \mathrm{~s}^{-1}$ after $30 \mathrm{~min}$ of dark adaptation. After recording steady state fluorescence, a second $0.8 \mathrm{~s}$ saturating light of $8000 \mu \mathrm{mol}$ photons $\mathrm{m}^{-2} \mathrm{~s}^{-1}$ was provided to determine the maximum fluorescence in the light-adapted state (Fm'). After turning off the actinic light, $3 \mathrm{~s}$ of far red light was followed by noting the minimal fluorescence in the light-adapted state (Fo'). The following parameters were then

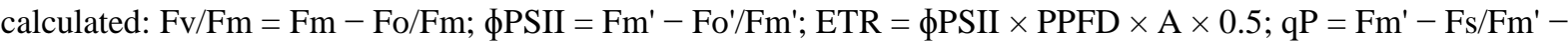
Fo'; $\phi N P Q=(F s / F m ')-(F s / F m) ; \phi f, d=F s / F m$. The inflexion temperature and the peak temperature were determined by using Junior PAM-250 (WALZ, Germany). Dark adapted leaf disc were kept in water bath of 
$25^{\circ} \mathrm{C}-60^{\circ} \mathrm{C}$ and readings were taken after every degree rise in temperature.

\subsection{Total Chlorophyll Estimation}

Total chlorophyll was estimated fluorometrically by taking $100 \mathrm{mg}$ leaf tissue in $20 \mathrm{ml}$ of dimethylsulphoxide (DMSO) at $65^{\circ} \mathrm{C}$ for $4 \mathrm{~h}$ in dark and total chlorophyll content was calculated [32].

\subsection{Membrane Injury Index}

Membrane Injury Index was measured with 100mg fresh leaf tissue in $20 \mathrm{~mL}$ milli-Q water per tube. Electrical conductivity (EC) was measured with an EC-meter (Eutech, Singapore). Test tubes were autoclaved for $10 \mathrm{~min}$ at $0.10 \mathrm{MPa}$ pressure to release all the electrolytes. Final EC was measured after bringing down the temperature to $25^{\circ} \mathrm{C}$. Percentage Relative Injury Index (RII \%), was than calculated [33].

\subsection{Real Time Expression Analysis}

Total RNA was isolated from control and treated samples using the RNeasy Plant mini kit (Qiagen, Germany) according to the manufacturer's instructions, followed by on-column DNase I treatment to remove genomic DNA contamination. $1.5 \mu \mathrm{g}$ of the total RNA was used as template for cDNA synthesis employing the High Capacity cDNA Archive kit (Applied Biosystems, USA) and mixed with $200 \mathrm{nM}$ of forward and reverse primers (Table 1) and SYBR Green PCR Master Mix (Agilent) for real time PCR analysis. Normalization of PCR was done by using internal control, actin. Three independent RNA isolations (biological replicates) were used for expression analysis.

\subsection{Seed Weight}

The mature spikes having fully developed grains were harvested from experimental and control plants and 100 seed weight was measured.

\subsection{Heat Susceptible Index (HSI)}

Heat Susceptible Index was calculated [34] using the following equation HSI $=(1-\mathrm{Xh} / \mathrm{X}) /(1-\mathrm{Yh} / \mathrm{Y})$, where $\mathrm{Xh}$ and $\mathrm{X}$ are the mean of physiological trait for each cultivar under heat stressed and control conditions, respectively. Whereas, Yh and Y are the physiological mean of all genotypes under heat stress and control conditions. The values for heat susceptibility index was used for generation of a heat map.

\subsection{Statistical Analysis}

All experiments were carried out with at least 3 biological replicates. Results were analyzed by one-way ANOVA to identify significant differences between the groups and their significance levels $(p<0.05)$ were determined.

\section{Results}

Terminal heat stress can substantially reduce grain yield depending upon the cultivar in wheat. Previous reports have shown the positive impact on grain yield upon application of various compounds. Hence in this study, the role of different compounds in ameliorating the negative effect of high temperature stress was investigated.

\subsection{Germinating Stage}

A tolerant (CPAN1676) and susceptible (HD2428) cultivars were selected based on their thermotolerance performance studied earlier in the lab. Different compounds were checked for their ameliorating effect, including Calcium Chloride $\left(\mathrm{CaCl}_{2}\right)$, Abscisic acid (ABA), Salicylic acid (SA), Brassinosteroid (BR), and 1-aminocyclopropane-1-carboxylic acid (ACC) which were previously reported to be providing thermotolerance to plants. Hence we have used different concentrations for optimization of ameliorating effect, if any, on heat stress in wheat cultivars.

Seeds were imbibed for $16 \mathrm{~h}$ with or without ameliorating compounds. Application of calcium chloride at 
Table 1. List of qRT-PCR primers used in the experiment.

\begin{tabular}{|c|c|c|}
\hline Gene & Primer & Sequence (5'-3') \\
\hline \multirow{2}{*}{ Ascorbate peroxidase } & $\mathrm{F}$ & ATGCGCCCCCATCATG \\
\hline & $\mathrm{R}$ & CACCAGTTCTTGTGTTCACATCATAG \\
\hline \multirow{2}{*}{ Rubisco Large subunit } & $\mathrm{F}$ & AACGAAGGGCGCGATCTT \\
\hline & $\mathrm{R}$ & CATTTGCAAGCTGCTCGGATA \\
\hline \multirow{2}{*}{ Rubisco small subunit } & $\mathrm{F}$ & ССTTCTCСTTGTGTTAGCATCGA \\
\hline & $\mathrm{R}$ & TTGCACGGATGACCATTAGG \\
\hline \multirow{2}{*}{ Oxygen evolving complex } & $\mathrm{F}$ & AGCCGCTCATCGACAAGAA \\
\hline & $\mathrm{R}$ & CCTGAGGCGGAGGTCGTT \\
\hline \multirow{2}{*}{ PsbO } & $\mathrm{F}$ & AGGCCGAGGGCATCCA \\
\hline & $\mathrm{R}$ & ACGGGTCATGAGCTTGGTTT \\
\hline \multirow{2}{*}{ PsbP } & $\mathrm{F}$ & AAGGCGCAACGAGACAAGAG \\
\hline & $\mathrm{R}$ & CGGCGTTCTCGACGAACTT \\
\hline \multirow{2}{*}{ Actin } & $\mathrm{F}$ & CCTTGTTTGCGACAATGGAA \\
\hline & $\mathrm{R}$ & AGCCCTTGGTGCATCATCTC \\
\hline
\end{tabular}

various concentration $(1 \mathrm{mM}, 5 \mathrm{mM}$ and $10 \mathrm{mM})$ showed an increase in percentage survivability of imbibed seeds as compared to imbibed heat treated seeds with temperature stress at $37^{\circ} \mathrm{C} / 1.5 \mathrm{~h}$ followed by $51^{\circ} \mathrm{C}$ for $3 \mathrm{~h}$ (Figure S1). Over the period of time, the lethal temperature stressed untreated plants progressively became more stunted as compared to $\mathrm{CaCl}_{2}$ treated plants. Heat treated CPAN1676 and HD2428 showed a decrease in percentage survivability of $42.5 \%$ and $70 \%$ whereas $\mathrm{CaCl}_{2}$ treated germinating seeds showed an increased percentage survivability at all concentrations (Figure S1), with maximum increase in survivability observed at $1 \mathrm{mM}$ and $5 \mathrm{mM} \mathrm{CaCl}_{2}$. At a concentration of $1 \mathrm{mM} \mathrm{CaCl}_{2}, C P A N 1676$ and $H D 2428$ showed a decrease in percentage survivability of $22.5 \%$ and $50 \%$, respectively (Figure S1).

Treatment with different concentrations of Brassinosteroid (BR) $(0.01 \mu \mathrm{M}, 0.05 \mu \mathrm{M}$ and $0.1 \mu \mathrm{M})$ showed a concentration of $0.01 \mu \mathrm{M}$ to be most effective in imparting thermotolerance to seedlings following lethal temperature stress (Figure S1).

Heat treated plants showed a percentage decrease in survival of $27.5 \%$ and $75 \%$ for CPAN1676 and HD2428 whereas BR $(0.01 \mu \mathrm{M})$ treated seeds showed a decrease in percentage survivability of $7.5 \%$ and $55 \%$ for CPAN1676 and HD2428, respectively (Figure S1).

Out of the different concentrations ( $100 \mu \mathrm{M}, 500 \mu \mathrm{M}$ and $1000 \mu \mathrm{M})$ of salicylic acid, a concentration of 100 $\mu \mathrm{m}$ showed a slightly better performance as compared to heat treated germinating seeds (Figure S1). Heat treated germinating seeds showed a decrease in percentage survival of $40 \%$ and $77.5 \%$ for CPAN1676 and HD2428, whereas salicylic acid (SA) $(100 \mu \mathrm{M})$ treated germinating seeds showed a percentage decrease in survival of $12.5 \%$ and $67.5 \%$ for CPAN1676 and HD2428, respectively (Figure S1).

Abscisic acid $(A B A)$ at a concentration of $5 \mu \mathrm{M}$ showed dramatic increase in percentage survivability in CPAN1676 reaching upto $97.5 \%$ whereas $H D 2428$ showed a lower survivability percentage of $50 \%$ in ABA treated germinating seeds, whereas heat treated germinating seeds showed a percentage survival of $27.7 \%$ and 77.5\% for CPAN1676 and HD2428, respectively (Figure S1).

1-aminocyclopropane-1-carboxylic acid (ACC) at a concentration of $100 \mu \mathrm{M}$ was used and the treated plants showed better recovery in terms of percentage decrease in survivability with heat treated plants showing a percentage decrease in survival of $27.5 \%$ and $77.5 \%$ in CPAN1676 and HD2428, respectively, whereas ACC treated germinating seeds showed a percentage decrease in survival of $12.5 \%$ and $52.5 \%$ in CPAN1676 and HD2428, respectively (Figure S1).

\subsection{Mature Plant Stage}

Since treatment with $\mathrm{CaCl}_{2}$ and $\mathrm{BR}$ increased the percentage survival of germinating seeds, both these com- 
pounds were used approximately a day before anthesis to check their ameliorating effect after heat treatment. Hence we have used $\mathrm{CaCl}_{2}$ at a concentration of $10 \mathrm{mM}$ and Brassinosteroid (BR) at a concentration of $0.05 \mu \mathrm{M}$, since BR at a concentration of $0.01 \mu \mathrm{M}$ did not showed optimal results in mature plants. This was probably due to the limitation in BR entry inside the plant through the surface upon foliar spray. The experiment was designed over a span of 5 days, with moderate temperature stress of $37^{\circ} \mathrm{C} / 1 \mathrm{~h}$ followed by high temperature stress of $43^{\circ} \mathrm{C}$ for $8 \mathrm{~h}$ were given on D-1 and D-3. D-2, D- 4 and D-5 are the recovery period at $22^{\circ} \mathrm{C} \pm 1^{\circ} \mathrm{C}$. Schematic representation of the experimental design along with the recovery plants on day 5 are shown in Figure 1.

\subsection{Photosystem II Efficiency}

In mature plants, high temperature has profound effect on photosynthetic yield measured as fluorescence efficiency (Fv/Fm) (Figure 2). All cultivars showed a decrease in Fv/Fm after heat treatment on D-1 and D-3, whereas by D-5, wheat cultivars C306 and K7903 showed complete recovery while HD2329 showed a continuous decrease in Fv/Fm which kept decreasing till D-5, pointing towards irreversible damage to the photosynthetic apparatus.

\subsection{Minimum Fluorescence}

The minimum fluorescence (Fo) showed a small increase after thermal stress on D-1 and D-3 in all cultivars, although the increase was slightly higher in HD2329 and PBW343 as compared to C306 and K7903 (Figure 3).

A steep increase in Fo was observed on D-4, in all cultivars, with sensitive cultivars HD2329 and PBW343 showing higher Fo values as compared to the tolerant cultivars C306 and K7903. All except HD2329 showed recovery by D-5, with treated plants showing faster recovery, HD2329 showed an increasing trend in Fo which reached to maximum level by D-5 with the treated plants too showing a similar trend. A slight decrease in Fo was observed in treated plants as compared to HS, suggesting irreversible damage to chloroplast membrane (Figure 3).

Thermal stress induced injury to PSII have been earlier shown [35]. Our results are consistent with earlier report in Vitis [6], where high temperature episodes caused inhibition of PSII activity. By D-5 of HS, both C306 and K7903 showed higher $\phi P S I I$ and ETR as compared to PBW343 and HD2329.

\subsection{Electron Transport}

Additionally, both PSII and ETR showed a consistent decrease in efficiency after high temperature treatment (Figure 4). Highest decrease in both these parameters were observed on D-1 and D-3, whereas by D-5 all except HD2329 showed recovery to various levels with treated plants showing faster recovery. HD2329 showed a steep decrease in $\phi P S I I$ and ETR starting from D-3 which kept decreasing till D-5.

The BR and $\mathrm{CaCl}_{2}$ treated plants showed stability by D-5 as compared to HS plants in HD2329. This suggests that treated plants had undergone relatively lesser injury as compared to non-treated plants. The faster recovery in treated plants results in better energy utilization, which over the span of the growing season adds to a significant increase in yield. Excess energy dissipated thermally is a photo protective mechanism in plants.

\subsection{Energy Distribution}

Energy partitioning model have earlier been proposed by giving insight into the energy assimilation and dissipation mechanism for protecting photosynthetic apparatus [36]. $\phi \mathrm{f}, \mathrm{d}$ (Steady state fluorescence) which depicts the total absorbed energy lost as heat and as chlorophyll fluorescence showed complete recovery by D-5 with treated plants showing similar trend (Figure 5).

High temperature induced injury results in an imbalance between energy absorption and utilization. The energy not utilized in carbon assimilation can be easily directed in formation of Reactive Oxygen Species (ROS) which further degrades the photosynthetic apparatus [37]. Nonphotochemical quenching is one mechanism to prevent ROS formation.

Non photochemical quenching regulated by thylakoid lumen $\mathrm{pH}$ and PsbS showed a significant increase in all the four cultivars with HD2329 showing maximum increase in NPQ by D-5 (Figure 5). The amount of constitutive thermal dissipation ( $\phi \mathrm{f}, \mathrm{d}$ ) thus showed an increase after D-1 and D-3 in all the four cultivars. Since $\phi f$, $d$ points to the inevitable energy loss, C306 and K7903 seems to be better performer than PBW343 and HD2329. 

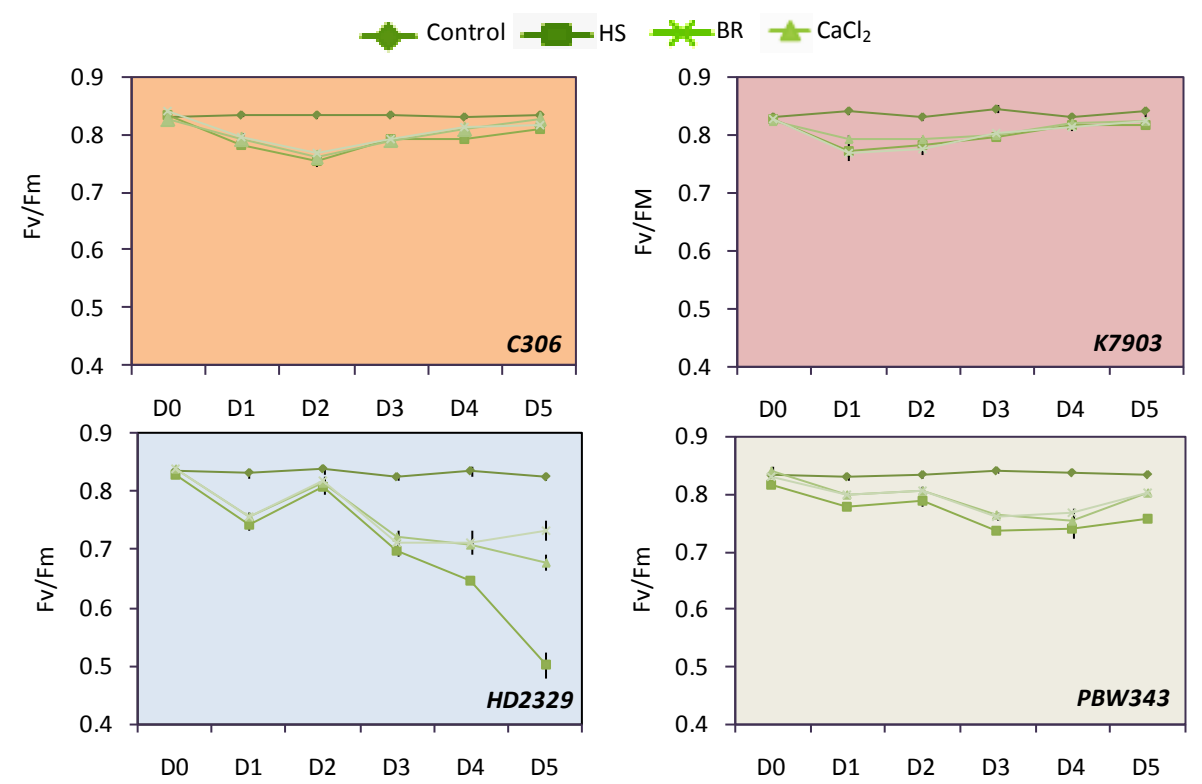

Figure 2. Fv/Fm in different wheat cultivars under heat treatment and recovery. Influence of exogenously applied compounds on $\mathrm{Fv} / \mathrm{Fm}$ in different wheat cultivars at control temperature $22^{\circ} \mathrm{C}$, during heat and recovery.
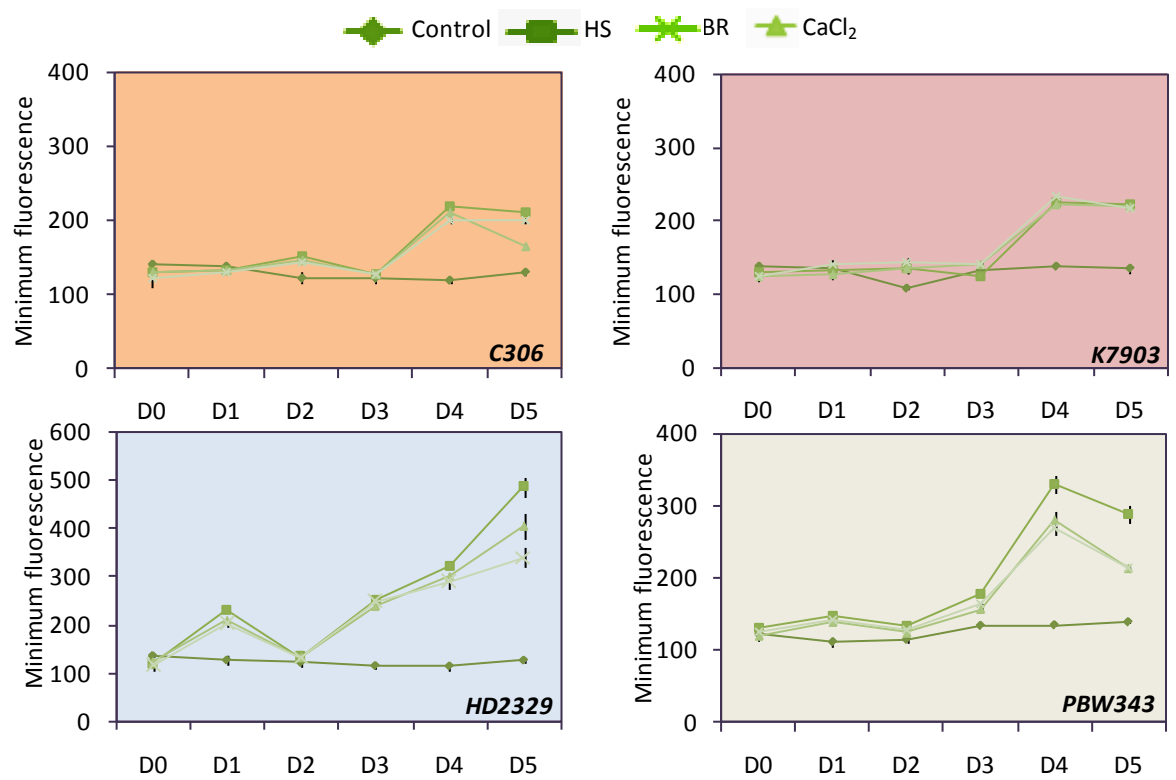

Figure 3. Minimum fluorescence in different wheat cultivars under heat treatment and recovery. Influence of exogenously applied compounds on minimum fluorescence in different wheat cultivars at control temperature $22^{\circ} \mathrm{C}$, during heat and recovery.

In fact HD2329 showed a maximum increase in $\phi \mathrm{f}$, $\mathrm{d}$ by D-5 suggesting damage to photosynthetic apparatus and chlorophyll, hence affecting energy absorption and utilization. Further, $\phi N P Q$ which depicts the fraction of the regulated $\triangle \mathrm{pH}$ and xanthophyll dependent thermal dissipation process ( $\$ \mathrm{NPQ})$, showed an increase after D-1 and D-3 and by D-5 showed different levels of increase in C306, K7903, HD2329 and PBW343 (Figure 5).

These results indicate that C306 and K7903 are more efficient in regulating energy partitioning in PSII complexes to minimize damaging potential simultaneously retaining the efficiency for carbon assimilation. The effective energy partitioning could possibly be contributing to acclimation mechanism by withstanding higher temperatures in C306 and K7903. 


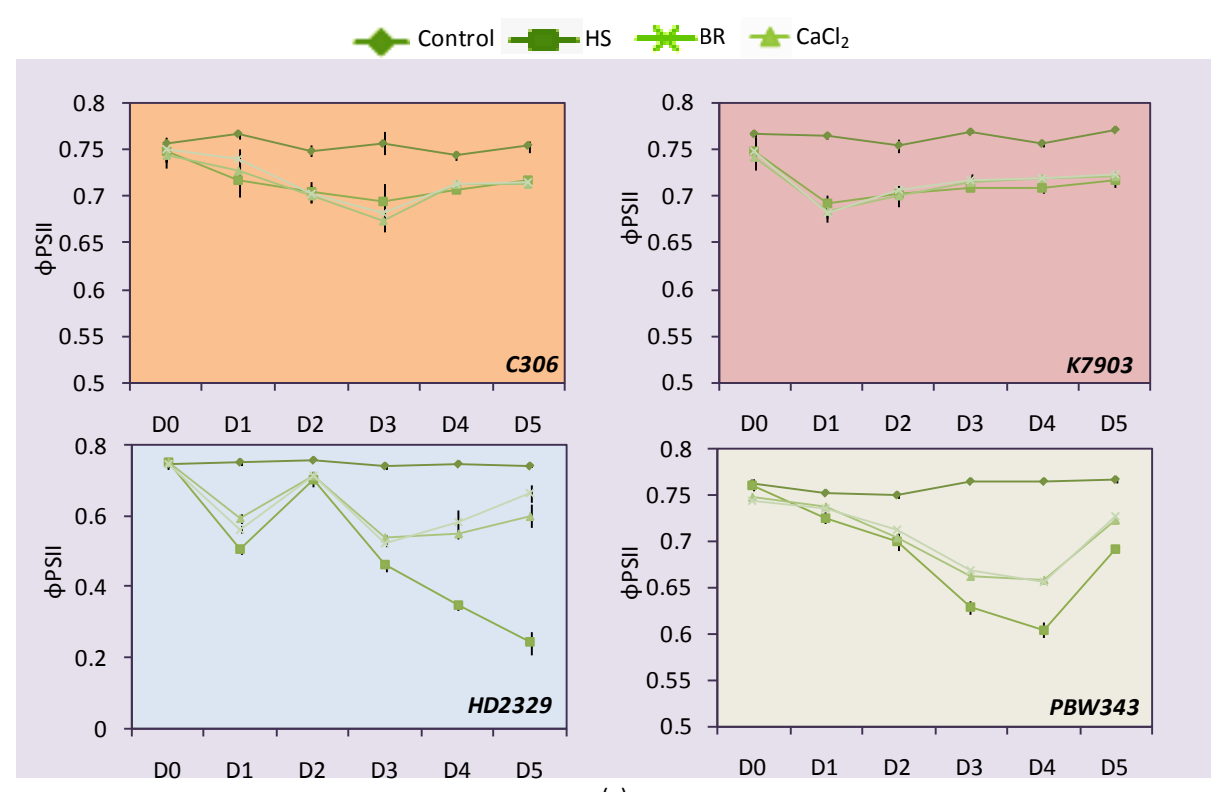

(a)
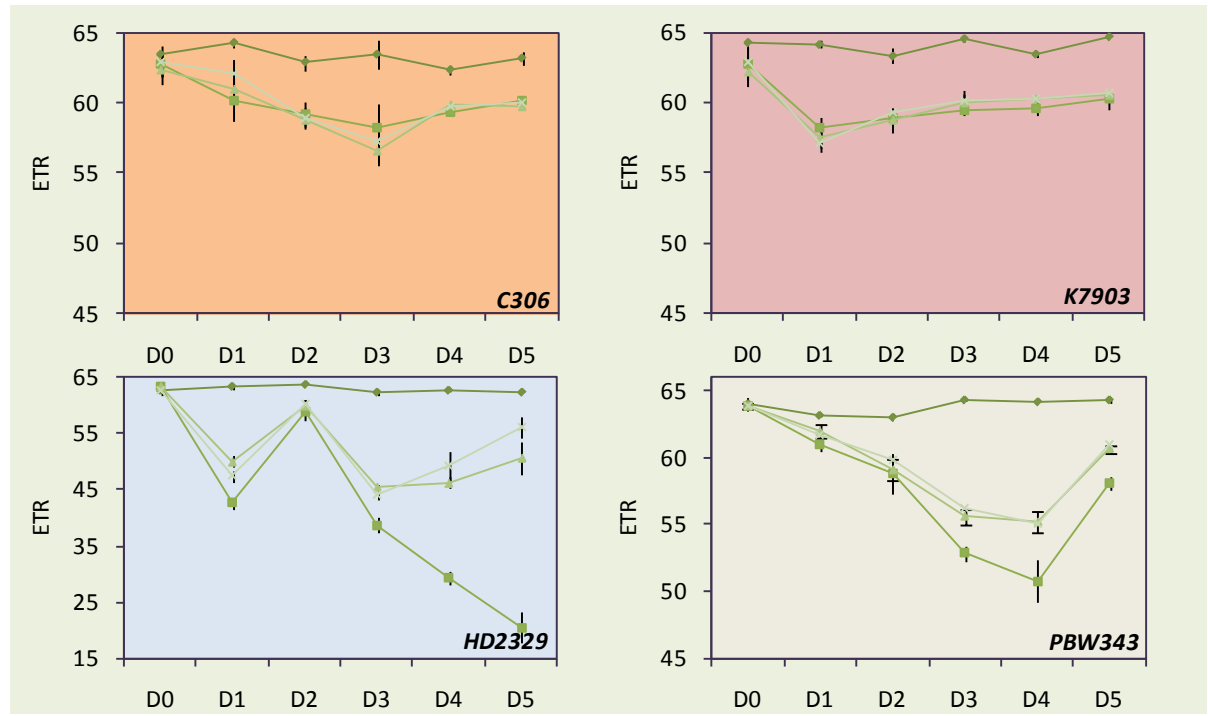

(b)

Figure 4. (a) $\phi P S I I$ and, (b) ETR, in different wheat cultivars under heat treatment and recovery. Influence of exogenously applied compounds on ETR in different wheat cultivars at control temperature $22^{\circ} \mathrm{C}$, during heat treatment and recovery.

\subsection{Light Quenching}

Decrease in qP (Photochemical quenching by PSII) was observed after D-1 and D-3 of heat stress, by D-5 all cultivars except HD2329 showed stability in qP. A consistent decrease in qP was observed in HD2329, although BR and calcium chloride heat stress treated plants showed comparatively stable qP by D-5 in HD2329 (Figure 6).

Following treatment, all cultivars showed faster recovery as compared to heat stressed plants. Estimation of redox state of QA, the first molecule that accept electron from PSII in z-scheme, using lake model presuming all photosynthetic units are connected [38], showed tolerant cultivars along with treatment given plants recovering faster as compared to the susceptible cultivars. qP indicates the proportion of reaction centres that are open. Earlier it has been used to indicate the onset of photo inhibition [39] and for determining the level of photo protective quenching of fluorescence [6]. 

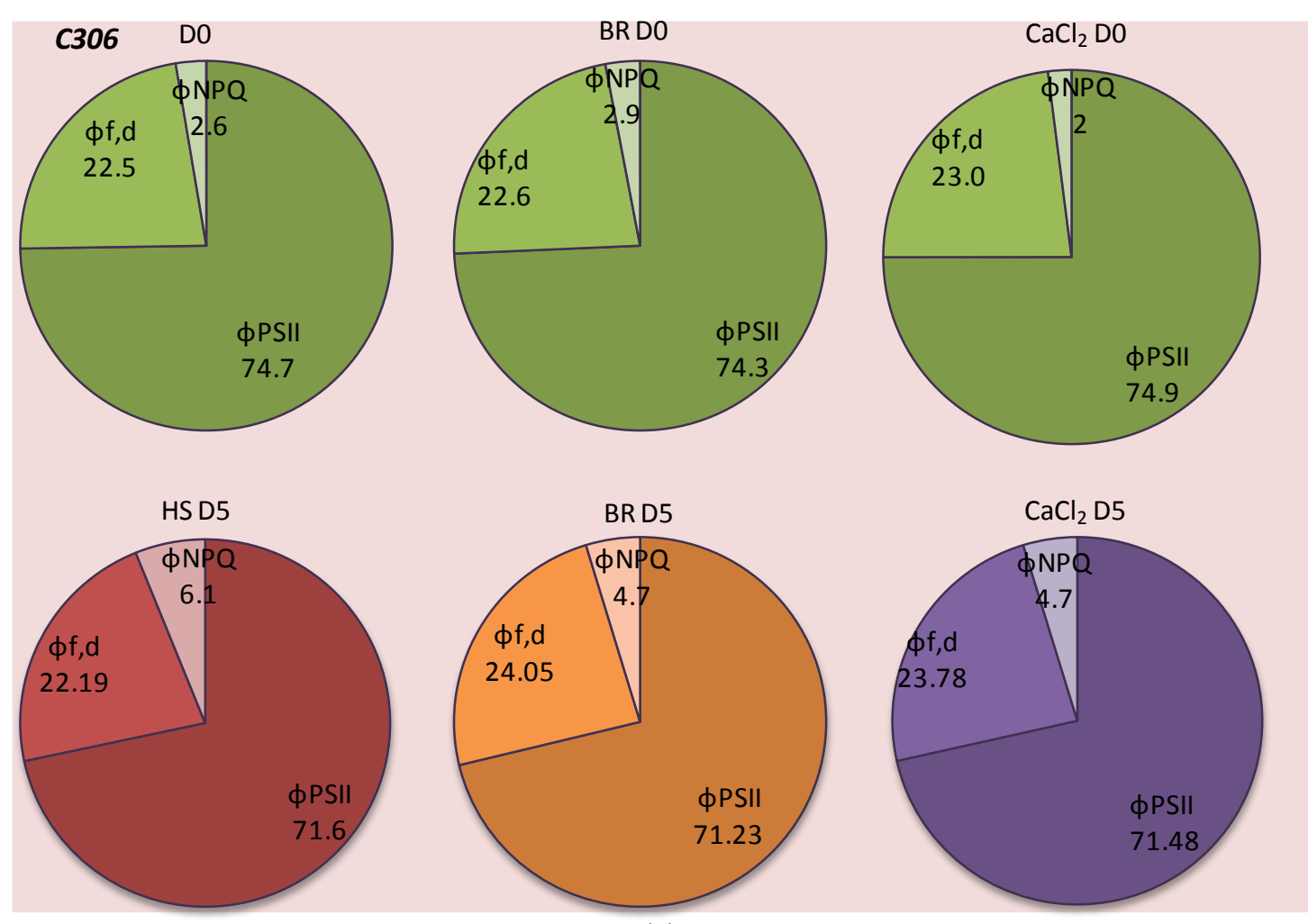

(a)
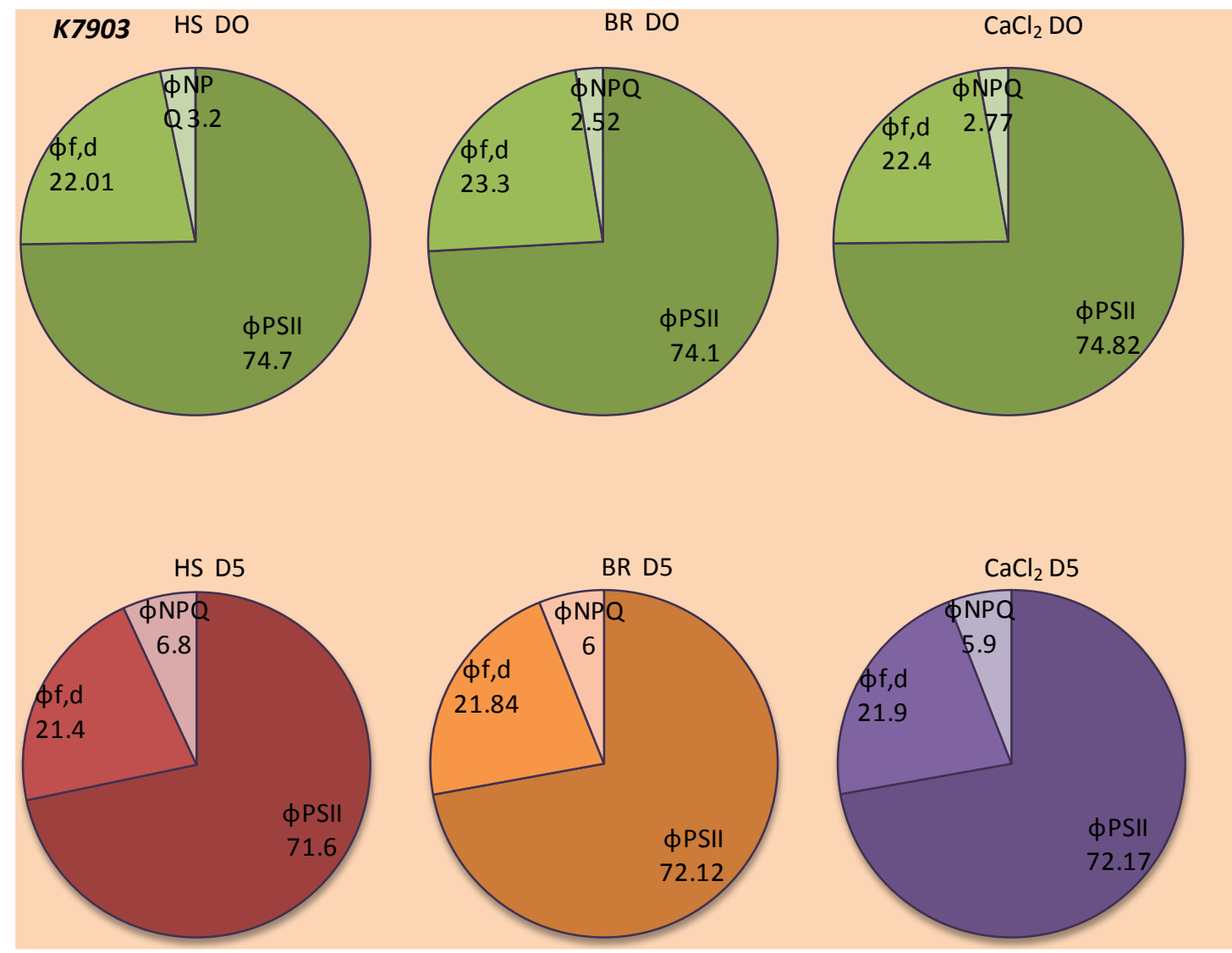

(b) 


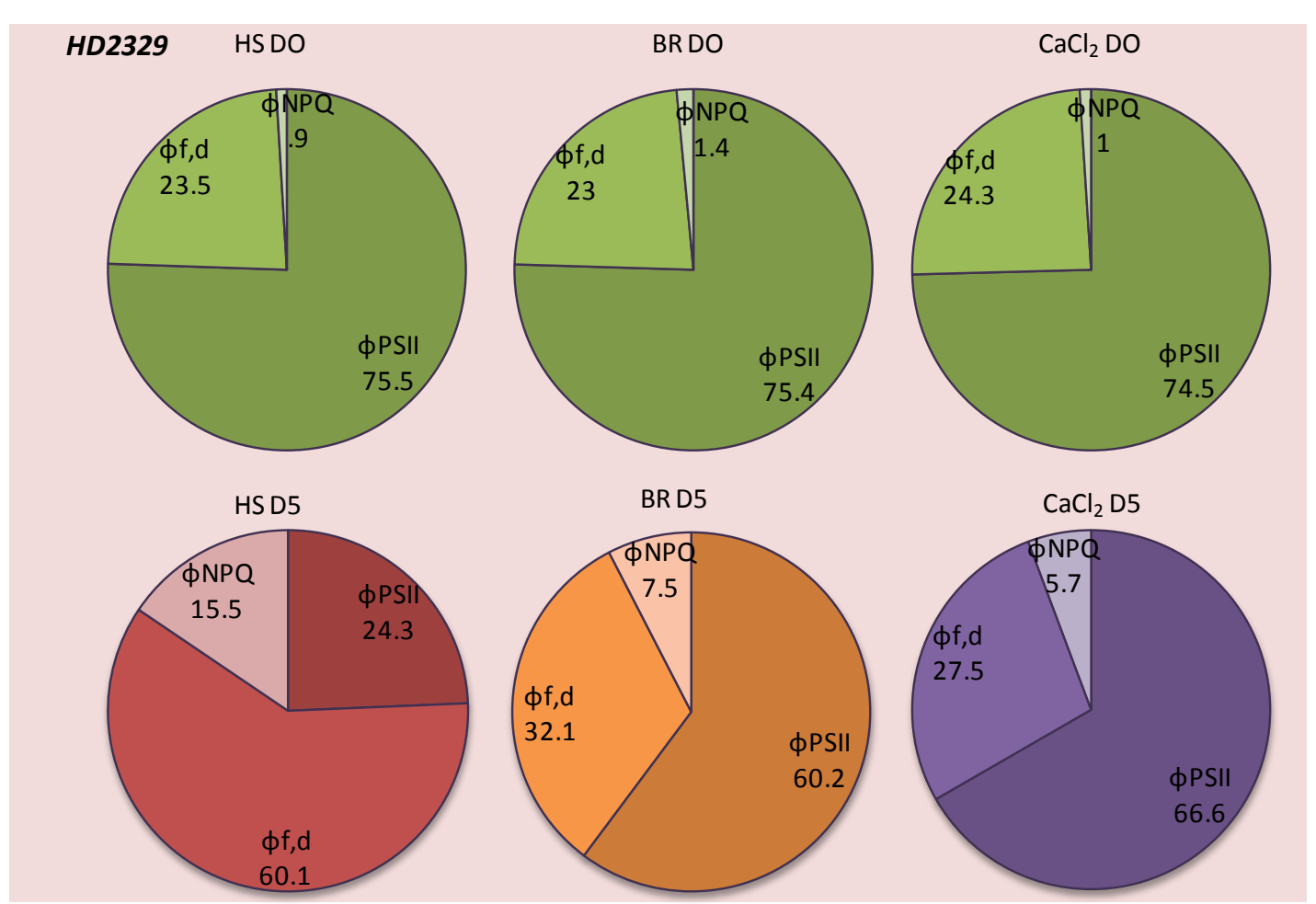

(c)

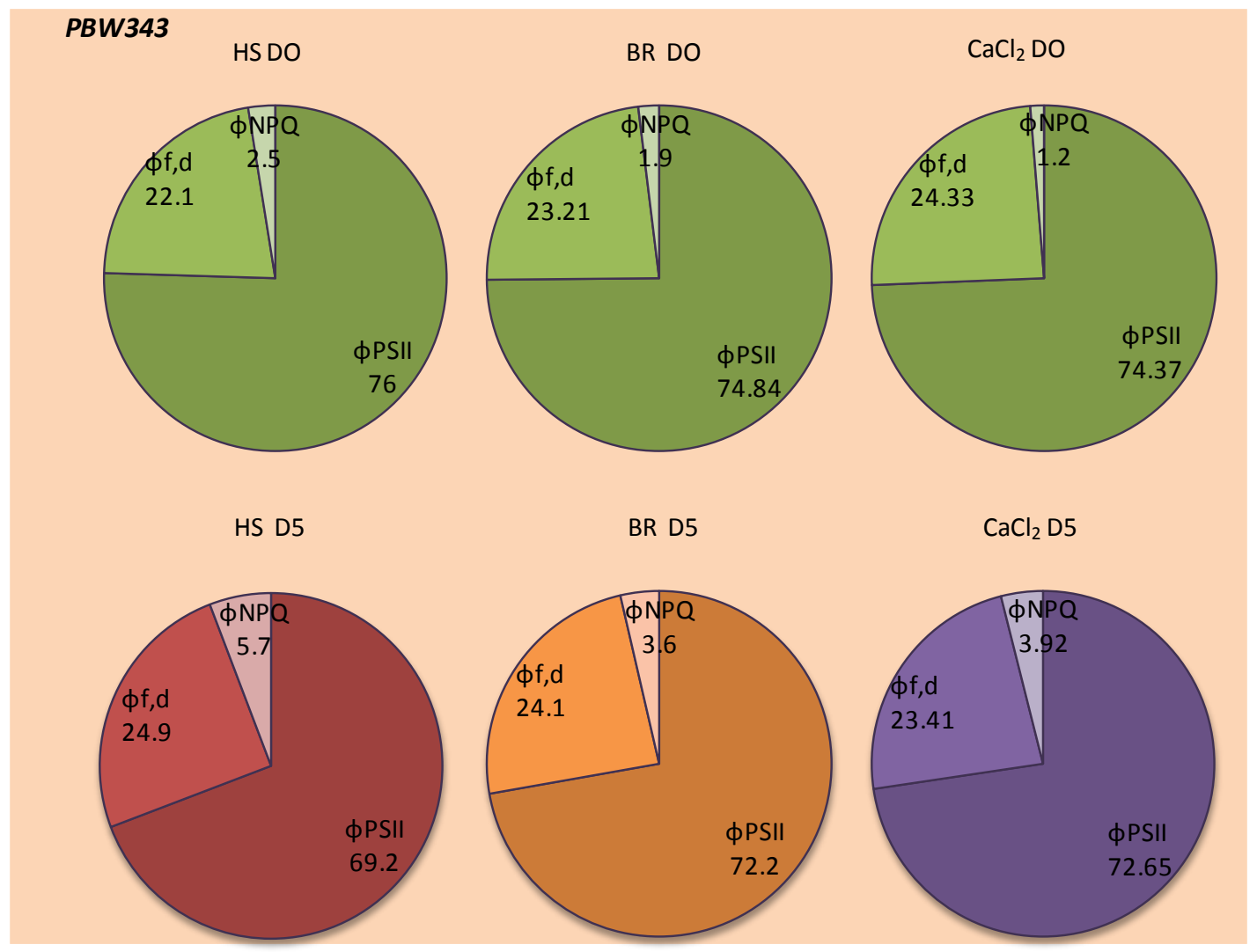

(d)

Figure 5. Energy distribution in different wheat cultivars under heat treatment and recovery phases. (a) C306; (b) K7903; (c) HD2329; (d) PBW343. 

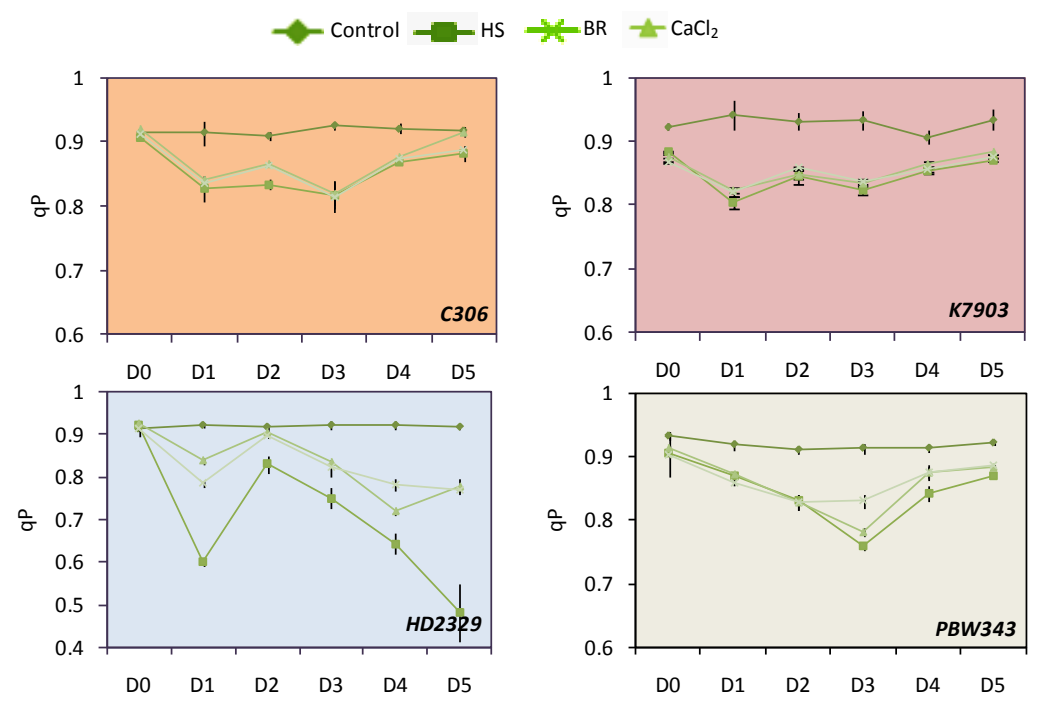

Figure 6. $\mathrm{qP}$ in different wheat cultivars under heat treatment and recovery. Influence of exogenously applied compounds on $\mathrm{qP}$ in different wheat cultivars at control temperature $22^{\circ} \mathrm{C}$, during heat and recovery.

\subsection{Membrane Thermo-Stability}

To measure the thermo-stability of the photosynthetic membranes, Fo versus $\mathrm{T}$ curves in the leaves of all four cultivars were measured (Figure 7). Fo versus $\mathrm{T}$ curve showed a parabola, with a higher inflection temperature (Ti) at which a steep rise in Fo is observed in both the tolerant cultivars and showed $\mathrm{Ti}$ of $46^{\circ} \mathrm{C}$ and $47^{\circ} \mathrm{C}$ in C306 and K7903 as compared to the susceptible cultivars $H D 2329$ and $P B W 343$, which showed a Ti of $40^{\circ} \mathrm{C}$ and $44^{\circ} \mathrm{C}$. No significant change in inflexion temperature was observed in any of the $\mathrm{BR}$ and $\mathrm{CaCl}_{2}$ treated plants. A corresponding increase in the peak temperature for Fo (Tp) was observed with K7903 showing higher peak temperature followed by $C 306$ and $P B W 343$ and $H D 2329$ showing minimum peak temperature of $52^{\circ} \mathrm{C}$, $52^{\circ} \mathrm{C}, 45^{\circ} \mathrm{C}$ and $51^{\circ} \mathrm{C}$, respectively (Figure 7).

For better efficiency of the photosynthetic apparatus, better membrane stability is advantageous. Increase in Fo in the dark under increasing temperature conditions (Fo versus $\mathrm{T}$ curve) has been frequently used to determine the thermo-stability of the photosynthetic apparatus [40]. Irreversible damage to photosynthetic apparatus can be predicted by noting the sharp increase in Fo (Ti) highlighting the critical point. In our study, we have observed tolerant cultivars C306 and K7903 having higher Ti as compared to susceptible cultivars HD2329 and PBW343, suggesting higher thermo-stability of photosynthetic apparatus in both tolerant cultivars.

\subsection{Light Avoidance}

The total chlorophyll content in both C306 and K7903 showed a slight dip on D-1 and D-3 but showed complete recovery by D-5. K7903 showed higher chlorophyll accumulation by D-5 as compared to control. In contrast, both HD2329 and PBW343 showed a continuous decrease in total chlorophyll. Although in all four cultivars, higher levels of chlorophyll was observed in BR and calcium chloride treated plants (Figure 8).

\subsection{Membrane Injury}

Membrane Injury Index has been widely used in identification of tolerant members of specie, highlighting the degree of damage to membrane. High temperature induced increase in membrane fluidity resulted in an increase in membrane leakage rate of all the four wheat cultivars after D-1 and D-3 of HS. Although by D-4, both C306 and K7903 started showing lower membrane injury and by D-5 showed nearly complete recovery (Figure 9).

Similar trend in MII was observed with BR and calcium chloride treated plants. HD2329 showed an increase in MII on D-4, which further increased on D-5, HD2329 treatment given plants with both the ameliorating agents too showed similar trend as of HS plants, with increase in membrane injury of 303 fold, 229 fold and 281 fold in $\mathrm{HS}, \mathrm{BR}$ and $\mathrm{CaCl}_{2}$ treated plants, respectively. In PBW343 HS, BR and calcium chloride treated plants a 


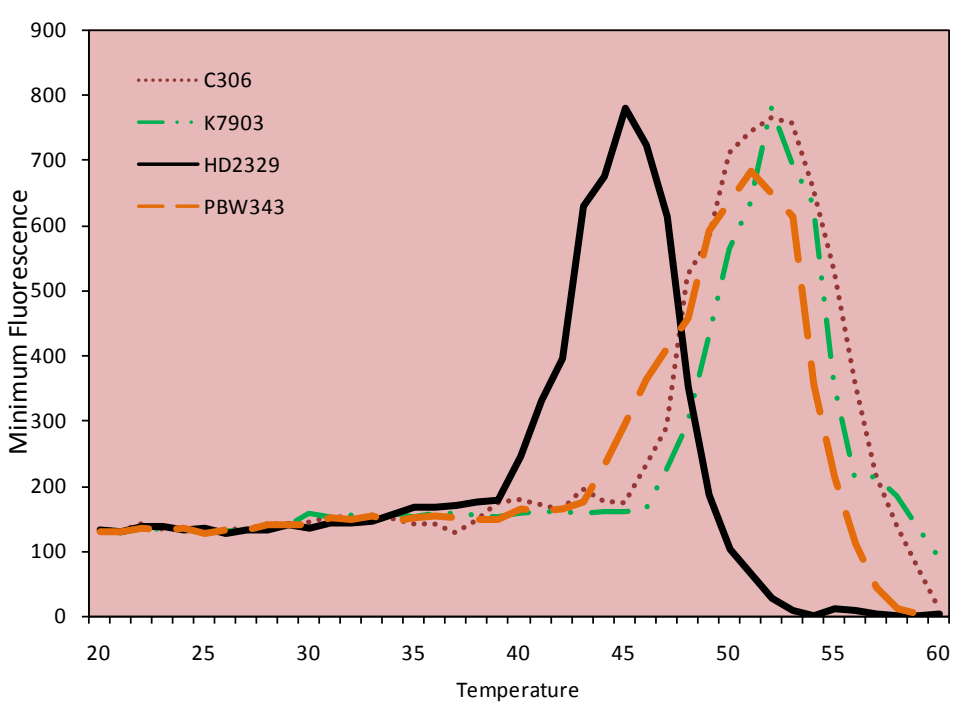

(a)

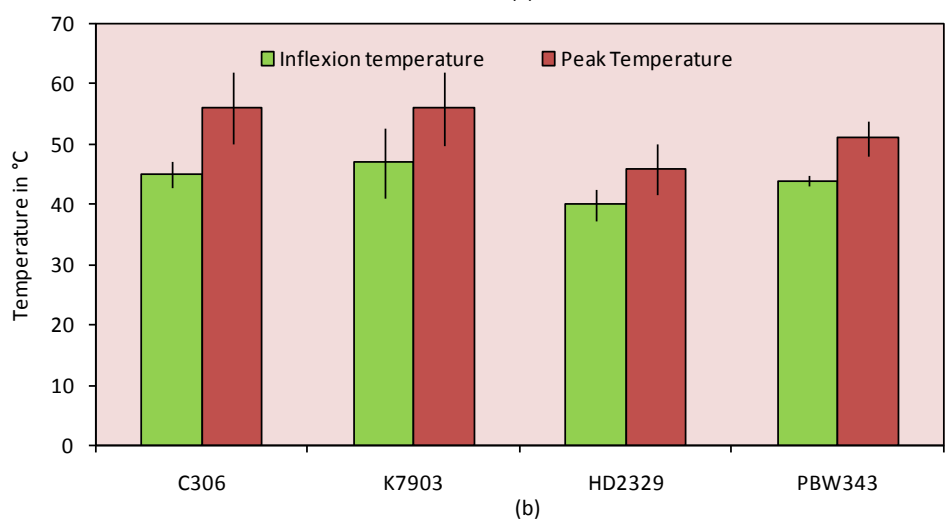

Figure 7. Fo v/s temperature in different wheat cultivars. (a) Ti (inflection temperature) and, (b) Tp (peak temperature) in leaves of different cultivars.

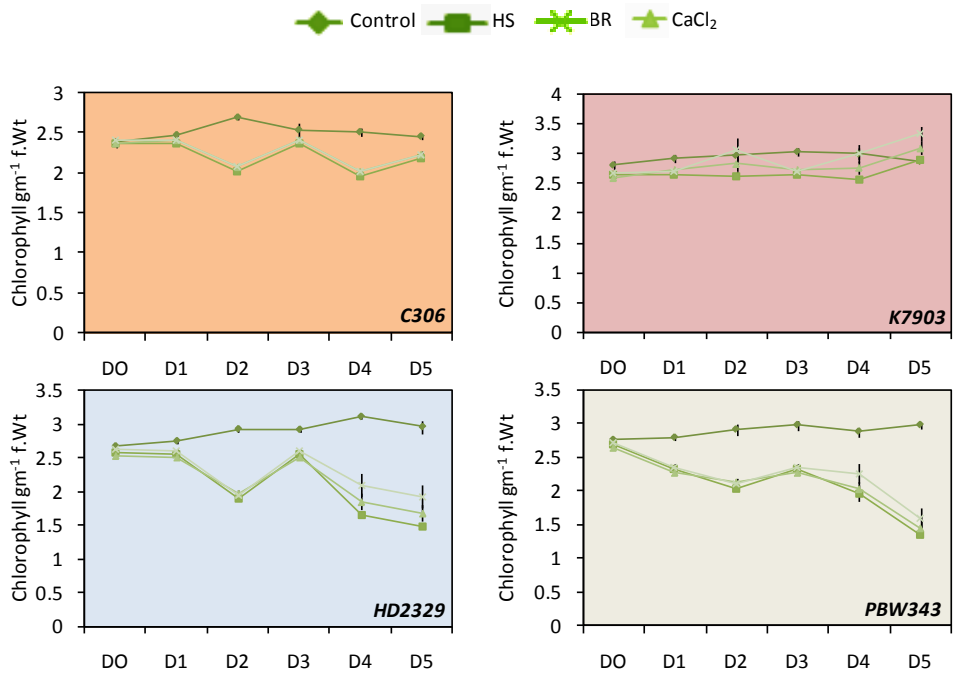

Figure 8. Total chlorophyll in different wheat cultivars under heat treatment and recovery. Influence of exogenously applied compounds on total chlorophyll in different wheat cultivars at control temperature $22^{\circ} \mathrm{C}$ and during heat treatment and recovery. 


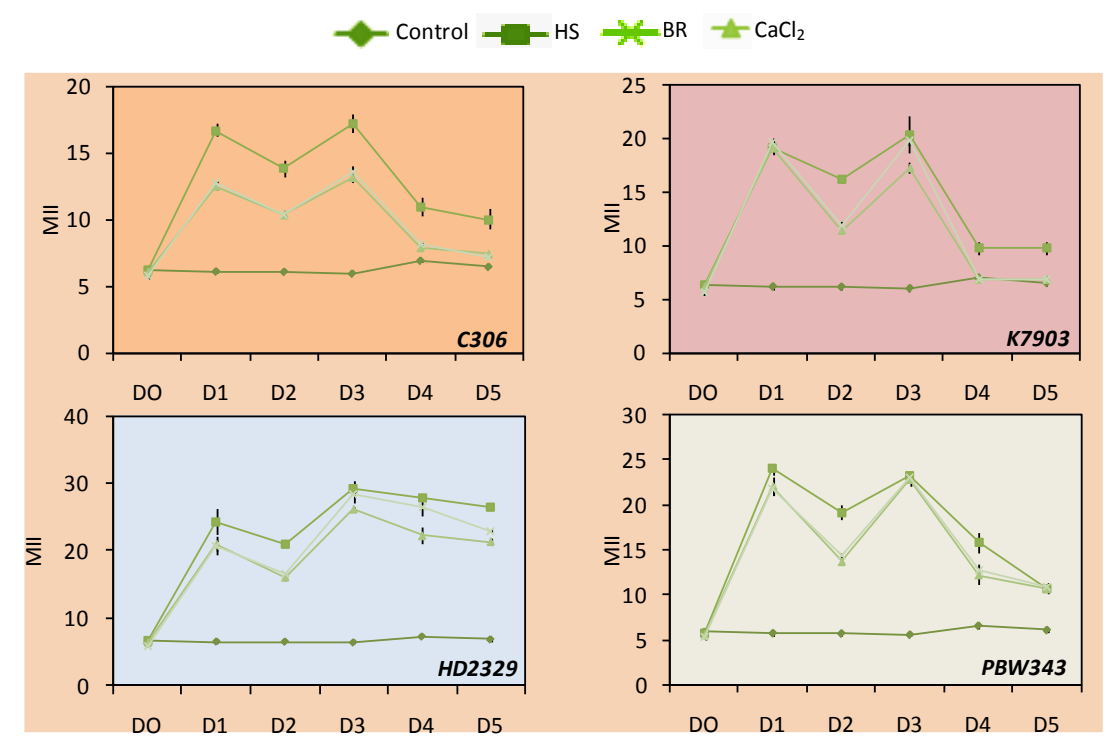

Figure 9. MII in different wheat cultivars under heat treatment and recovery. Influence of exogenously applied compounds on MII in different wheat cultivars at control temperature $22^{\circ} \mathrm{C}$ and during heat treatment and recovery.

similar increase in MII as HD2329 on D-4 was observed but started showing stability by D-5, with BR and $\mathrm{CaCl}_{2}$ treated plants showing slight decrease in injury as compared to HS (Figure 9). Better membrane stability under stress conditions will invariably be advantageous for the plant, since a part of light reaction of photosynthesis is membrane localized; a better membrane stability will help in efficient electron transport and an overall better performance of photosynthesis.

\subsection{Temperature Induced Seed Weight Variation}

The 100-seed-weight showed a higher percentage decrease in seed weight in susceptible cultivars HD2329 and PBW343 as compared to the two tolerant cultivars C306 and K7903 (Figure 10(b)). Upon treatment with BR and calcium chloride, all cultivars showed a significant increase in 100-seed-weight along with an increased size (Figure 10(a)). No difference was observed in seed weight in control plants treated with BR and calcium chloride (Figure S2).

\subsection{Gene Expression Analysis}

A substantial decline in the expression of all photosynthetic genes were observed in all cultivars immediately after heat stress, although the decrease in tolerant cultivars was slightly lower as compared to the two susceptible cultivars and faster recovery in the expression of the transcripts of all genes was observed in the tolerant cultivars along with treated plants of the four cultivars (Figure 11).

Expression analysis by real time PCR revealed a decrease in the expression of all photosynthetic genes in all cultivars after temperature stress on D-1 and D-3. For all genes under study namely rubisco large and small subunit, PsbO, PsbP, oxygen evolving complex and ascorbate peroxidase, both the tolerant cultivars showed faster recovery in expression of these genes as compared to the two susceptible cultivars. Faster recovery was also observed in all cultivars after treatment with BR and calcium chloride (Figure 11).

\subsection{Heat Injury Index}

Further to determine the thermos-tolerance level of all the four cultivars, Heat Susceptibility Index (HSI) was estimated (Figure 12). HSI depict the high temperature susceptibility of plant under the parameter in consideration. A higher index generally depicts high susceptibility towards particular stress. Thermo-tolerant cultivars showed a decrease in Heat Susceptibility Index (HSI) as compared to the two thermo-susceptible cultivars. Treatment with the ameliorating agents decreased the HSI in all cultivars to a considerable level (Figure 13). 


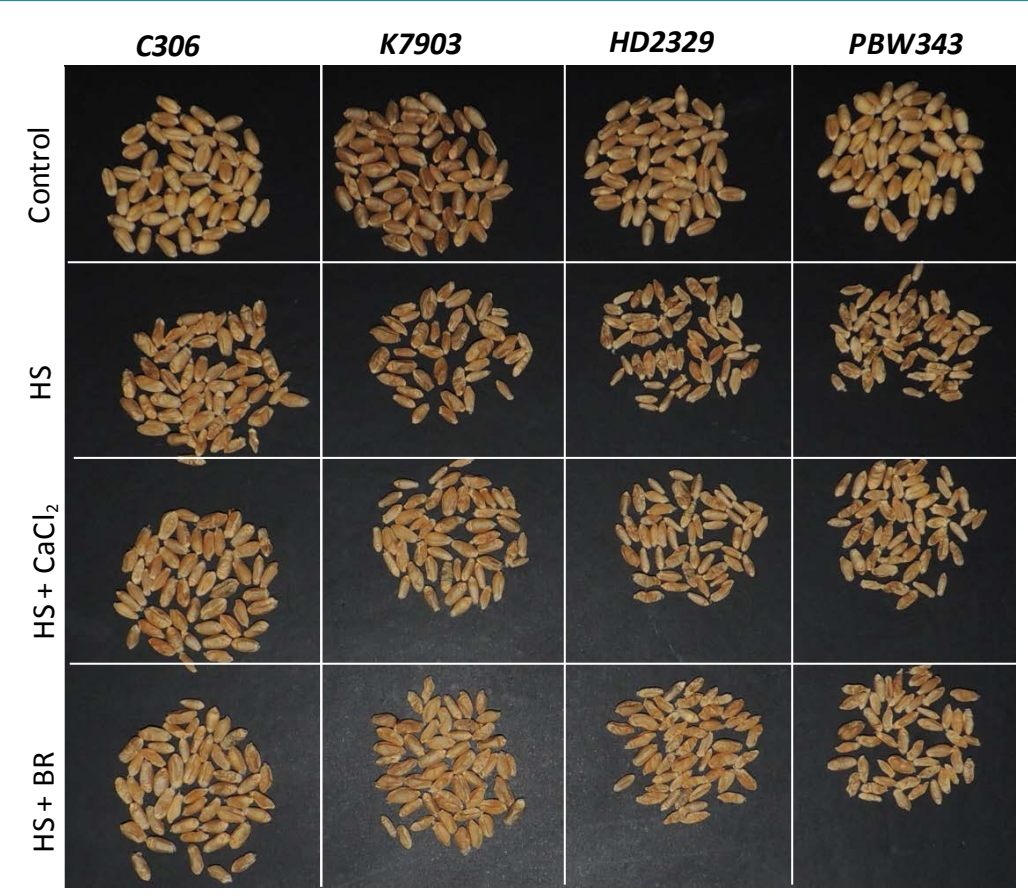

(a)

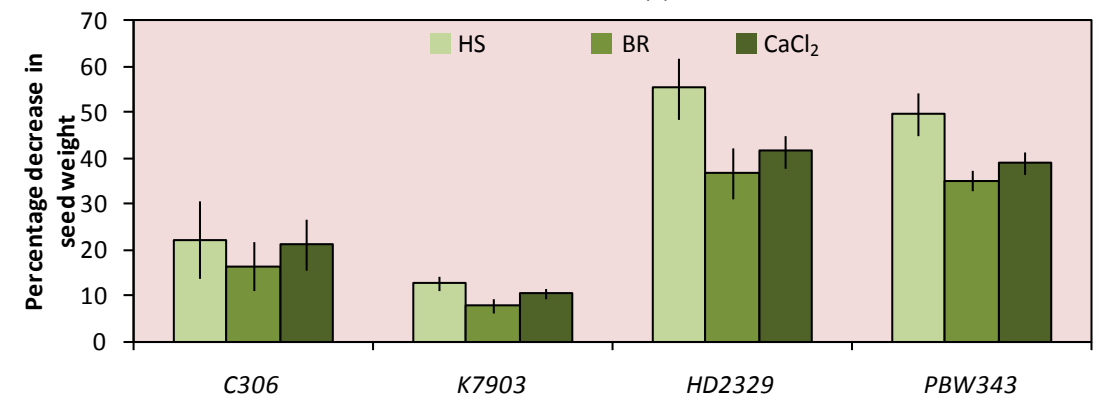

(b)

Figure 10. Influence of exogenously applied compounds including $\mathrm{CaCl}_{2}(10 \mathrm{mM})$ and BR $(0.05 \mu \mathrm{M})$ on (a) seed seed size; (b) seed weight in different wheat cultivars at control temperature $22^{\circ} \mathrm{C}$ and two episodes of high temperature stress of $37^{\circ} \mathrm{C}$ for $1 \mathrm{~h}$ followed by $43^{\circ} \mathrm{C}$ for $8 \mathrm{~h}$.

Heat Susceptibility Index for heat treated $H D 2329$ was maximum, although with $\mathrm{BR}$ and $\mathrm{CaCl}_{2}$ treatment HD2329 showed a decrease in HSI. Minimum HSI was shown by treated plants of K7903. Different cultivars responded differently to the ameliorating agents. Although C306 and HD2329 showed lower HSI with $\mathrm{CaCl}_{2}$, whereas K7903 showed low HSI with BR (Figure 13). These results suggest towards the possible cultivar dependent response of different ameliorating agents. Both the tolerant cultivars showed a comparatively low HSI as compared to the two susceptible cultivars.

\section{Discussion}

Earlier reports [31] [41] [42] have suggested the identification of tolerance level in different genotypes following exposure to a sub-lethal induction stress. This can chiefly be attributed to the changing transcriptome upon exposure to thermal stress [42] [43]. The prior treatment of germinating seeds and mature plants with moderately high temperature of $37^{\circ} \mathrm{C}$ in general can act as an inducer of the stress responsive pathways. Under natural conditions, the plants are exposed to a gradual increase in temperature and not directly to heat shock thereby suggesting that genetic variability for thermotolerance between cultivars can be observed only after exposure to an induction temperature. 


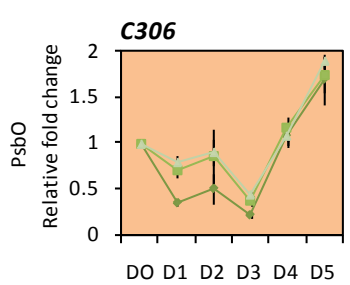

C306
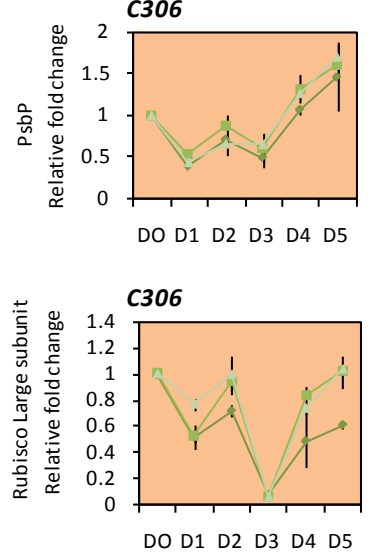

DO D1 D2 D3 D4 D5
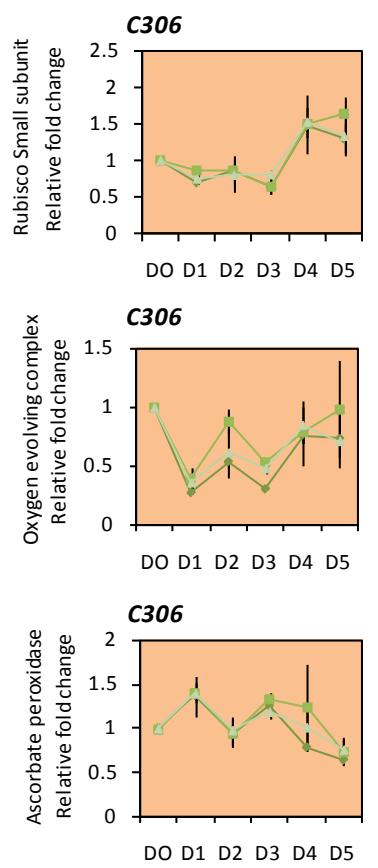

$\kappa 7903$

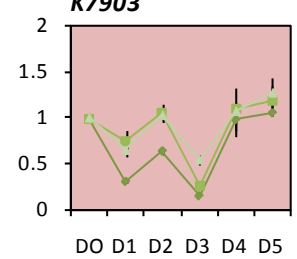

K7903
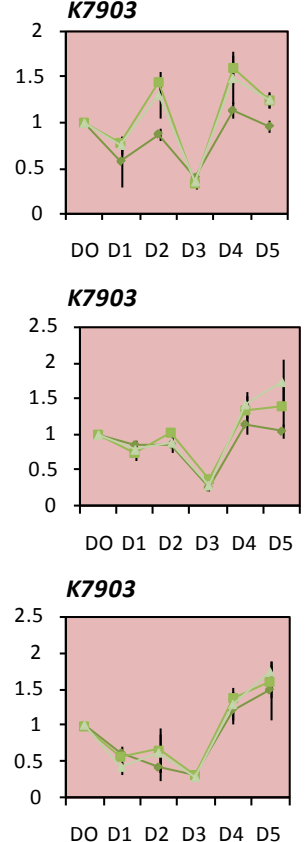

$\kappa 7903$

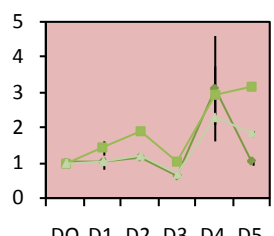

K7903

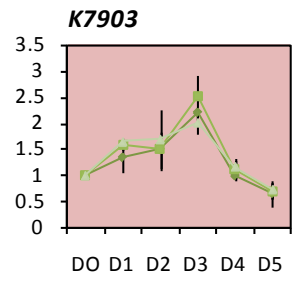

HD2329

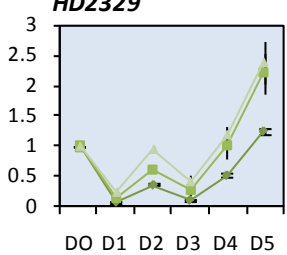

HD2329

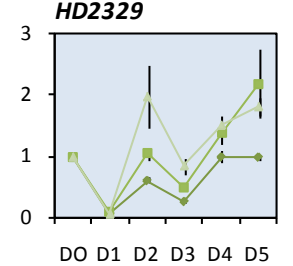

HD2329

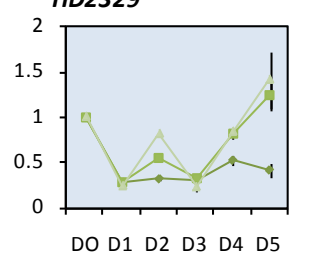

HD2329

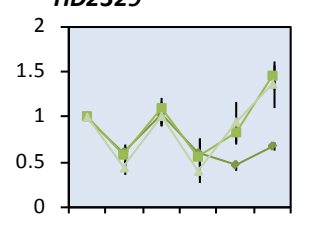

DO D1 D2 D3 D4 D5

HD2329

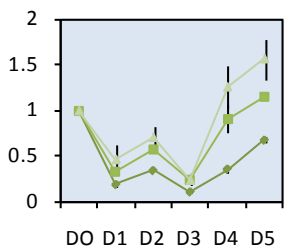

HD2329

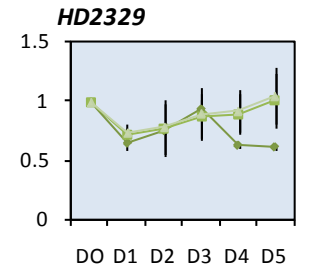

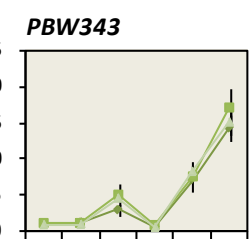

DO D1 D2 D3 D4 D5

PBW343

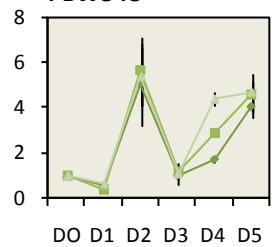

PBW343

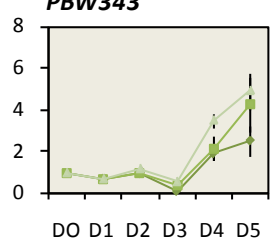

PBW343

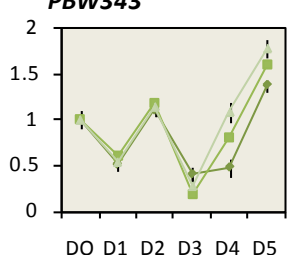

PBW343

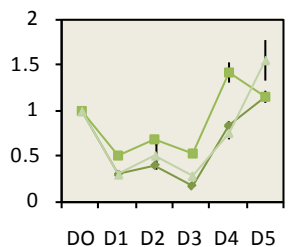

PBW343

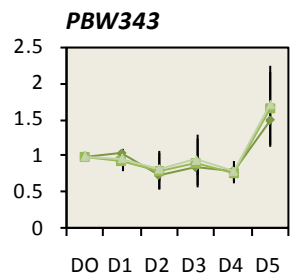

Figure 11. Differential expression of photosynthesis associated genes in different wheat cultivars under heat treatment and recovery.

The adverse effect of thermal stress on PSII had earlier been reported [35]. High temperature treatment resulted in a significant decrease in PSII function in all cultivars after D-1 and D-3 of heat stress. The observable changes in PSII and Fo are dependable diagnostic indicators of photosystem efficiency [44].

Estimation of reduced state of QA based on Puddle model reflect the reaction centres that are open and had been commonly used to indicate the onset of photo inhibition [39] and for determining the level of photo protective quenching of fluorescence [45].

The minimum fluorescence has been extensively used in thermo-stability of the photosynthetic apparatus [40] [46]-[48]. A sharp increase in Fo (Ti) indicates severe damage to photosynthetic apparatus [9]. In our study, we 


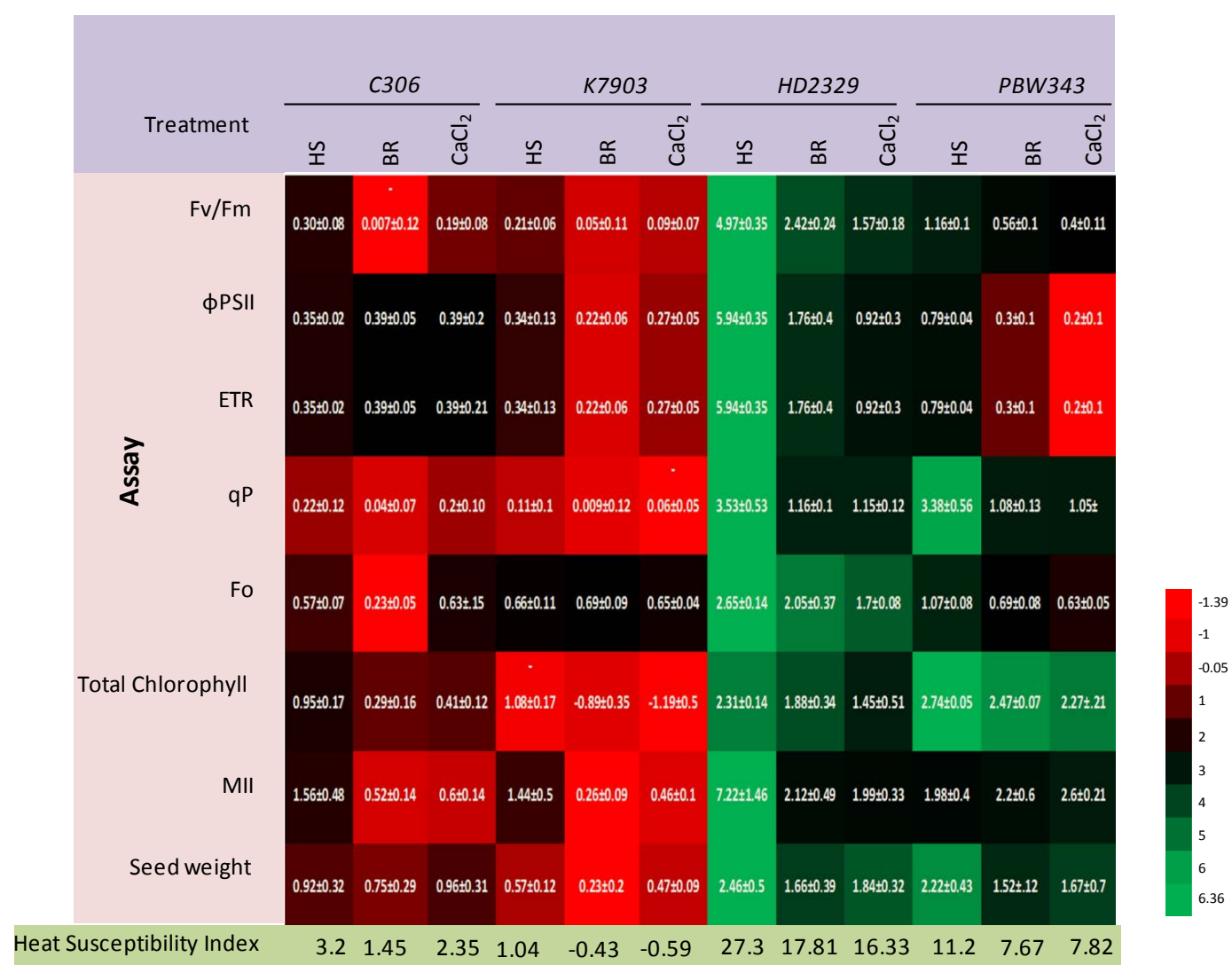

Figure 12. The Heat Susceptibility Index (HSI) for different parameters for HS and treatment given plants was calculated. Heat map depicting heat susceptibility of different parameters. Red colour depict minimum HSI and green colour depict maximum HSI.

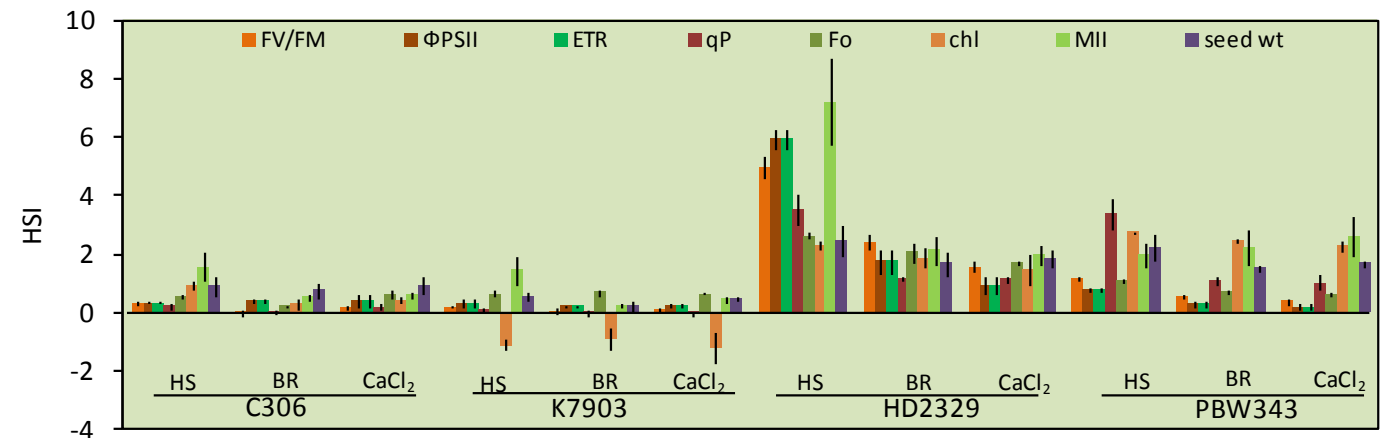

Figure 13. A comparative graph of heat stress and ameliorating agent treated cultivars. Vertical lines on top of bars indicate standard error of means.

found K7903 and C306 exhibited a higher Ti than the two thermo-susceptible cultivars HD2329 and PBW343 suggesting that K7903 and C306 have better thermo-stability of its photosynthetic apparatus as compared to the two thermo-susceptible cultivars HD2329 and PBW343.

High temperature induced photo inhibition result in an imbalance in light energy absorption and utilization. The energy not utilized can result in the formation of free radicals, which can damage the photosynthetic apparatus [37] [49]. The consecutive heat treatment showed a significant decrease in pigment content in the two susceptible cultivars $H D 2329$ and $P B W 343$, which is considered as a protective mechanism to decrease light absorption and hence energy imbalance. In fact a slight increase in total chlorophyll was observed in K7903 at the end of recovery. 
Cellular membrane are the chief sites for physiological injury by high temperature [50]. Hence membrane injury can be used as an indicator of the physiological state of the plant. Better membrane stability of C306 and K7903 might correlate with membrane composition. Membrane fluidity is generally dependent on membrane composition including unsaturation level of phospholipids and glycolipids [51]. Earlier reports have shown a correlation between membrane composition and PSII efficiency [52], since components involved in light reaction in plants are membrane embedded, hence a change in membrane fluidity will directly affect PSI and PSII complexes. The consistent increase in membrane injury index in HD2329 even tillD-5 shows its inability to recover after treatment with high temperature.

Lower decrease in 100-seed-weight was observed in thermo-tolerant cultivars as compared to thermo-susceptible cultivars after heat treatment. Upon application of ameliorating agents, considerable increase in 100seed-weight was observed in all cultivars. Increased yield in treated plants can be correlated with the better photosynthetic activity, since addition of ameliorating agents invariably resulted in an increase in PSII efficiency and ultimately photosynthetic yield. Any increase in photosynthetic activity will contribute to the assimilatory efficiency of plant, and hence will improve yield in terms of grain weight.

Light energy distribution showed different level of energy utilization between different cultivars. Whereas both the tolerant cultivars C306 and K7903 showed only a slight increase in $\phi \mathrm{f}$, d (Constitutive thermal dissipation), and $\phi N P Q$ (non photochemical quenching) by D-5, HD2329 showed a significant increase in both $\phi \mathrm{f}$, $\mathrm{d}$ and $\phi N P Q$, although PBW343 showed stability in $\phi \mathrm{f}$, d and $\phi N P Q$ by D-5. The increase in $\phi \mathrm{f}, \mathrm{d}$ in $H D 2329$ highlight the damaging effect of high temperature stress on the thylakoid membrane and thus resulting in a decrease in efficiency in energy utilization via PSII complexes and hence an increase in damage to carbon assimilation pathway.

A decrease in the transcripts level of genes involved in the process of photosynthesis was observed. A decrease in photosynthesis can possibly be an adaptive mechanism for high temperature tolerance in plants. Shut down of the carbon assimilation can possibly aid in imparting thermotolerance to plants by keeping a strong proton motive force, thus preventing membrane collapse. In addition, rubisco deactivation can avert photorespiration under conditions of high temperature and thus preventing the formation of phosphoglycolate and omit the carbon that could be fixed.

Environmental stress inducing ROS production triggers enhancement in APX expression [53] [54]. Under conditions of damaged PSII, higher expression of APX can scavenge the $\mathrm{H}_{2} \mathrm{O}_{2}$ as part of the ascorbate-glutathione or Asada-Halliwell-Foyer pathway [53].

\subsection{Role of BR in Stress Tolerance}

Various studies have highlighted BR induced abiotic stress tolerance in plants [19]-[21] [55] [56], however the precise mechanism of action remained enigmatic, primarily due to the strong and pleiotropic phenotypes of BR biosynthesis and signaling mutants, including extreme dwarfism, associated with dark green and epinastic leaves [55] [57]-[59]. Microarray analysis revealed BR induced expression of stress associated genes including heat shock protein and oxidative stress related genes in Arabidopsi [58] [60].

\subsection{Role of Calcium Chloride in Stress Tolerance}

Transient $\mathrm{Ca}^{2+}$ peaks have been observed across the plasma membrane during heat stress, corroborating the role of heat stress sensing by plasma membrane [61]-[64]. Rapid influx of $\mathrm{Ca}^{2+}$ was observed in plants treated with benzyl alcohol, a known membrane fluidizer, inducing a rapid influx of $\mathrm{Ca}^{2+}$ and a progressive expression of HSP's resulting in developing thermotolerance [63].

Increased expression of Cam3 and Cam7 is observed during thermal stress resulting in expression of HSPs [62] [65]. Cams further interact with calcium dependant kinases such as AtCBK3, resulting in the activation of HSFs, which further regulate HSP and thus impart thermotolerance to plants [63]. The HSF expression/regulation seems to be governed by membrane physiological state and perhaps triggered by increased fluidity of membrane, thus resulting in expression of different HSPs and also the change in proportion of saturated and unsaturated fatty acid. During recovery period, calcium treatment resulted in higher thermo-stability possibly due to the higher expression of stress associated genes especially anti-oxidative response.

In our study, we have observed that application of $\mathrm{BR}$ and $\mathrm{CaCl}_{2}$ on plants before heat stress can decrease the injury level and increase the recovery after heat stress. Faster recovery after heat stress in all the cultivars based 
on the florescence observation along with membrane injury index, total chlorophyll content and faster recovery of genes involved in photosynthesis points towards the ameliorating effect of BR. Further, higher seed weight observed in treated plants points towards the significance of these compounds in ameliorating the negative effect of heat treatment and an overall increase in grain yield.

\section{Conclusion}

In conclusion, the two thermo-tolerant cultivars, C306 and K7903 performed better under high temperature treatment as compared to the two thermosensitive cultivars HD2329 and PBW343. Exogenous application of Brassinosteroid and calcium chloride resulted in faster recovery in all the four cultivars.

\section{Acknowledgements}

This work was financially supported by Department of Biotechnology, Government of India, and partially by Indo-Swiss Collaboration in Biotechnology (ISCB). SH thanks Council for Scientific and Industrial Research for Junior and Senior Research Fellowships.

\section{References}

[1] IPCC (2007) Summary for Policymakers. In: Solomon. S., Qin, D., Manning, M., Chen, Z., Marquis, M., Averyt, K.B., Tignor, M. and Miller, H.L., Eds., Climate Change 2007: The Physical Science Basis. Contribution of Working Group I to the Fourth Assessment Report of the Intergovernmental Panel on Climate Change, Cambridge University Press, Cambridge.

[2] Wagner, D. (1996) Scenarios of Extreme Temperature Events. Climate Change, 33, 385-407. http://dx.doi.org/10.1007/BF00142585

[3] White, T.A., Campbell, B.D., Kemp, P.D. and Hunt, C.L. (2001) Impacts of Extreme Climatic Events on Competition during Grassland Invasions. Global Change Biology, 7, 1-13. http://dx.doi.org/10.1046/j.1365-2486.2001.00381.x

[4] Garcia-Plazaola, J.I., Esteban, R., Hormaetxe, K., Fernandez-Marın, B. and Becerri, J.M. (2008) Photoprotective Responses of Mediterranean and Atlantic Trees to the Extreme Heat-Wave of Summer 2003 in Southwestern Europe. Trees, 22, 385-392. http://dx.doi.org/10.1007/s00468-007-0199-y

[5] Wang, D., Heckathorn, S.A., Mainali, K. and Hamilton, E.W. (2008) Effects of N on Plant Response to Heat-Wave: A Field Study with Prairie Vegetation. Journal of Integrative Plant Biology, 50, 1416-1425. http://dx.doi.org/10.1111/j.1744-7909.2008.00748.x

[6] Luo, H.B., Ma, L., Xi, H.F., Duan, W., Li, S.H., Loescher, W., Wang, J.F. and Wang, L.J. (2011) Photosynthetic Responses to Heat Treatments at Different Temperatures and Following Recovery in Grapevine (Vitis amurensis L.) Leaves. PloS ONE, 6, 8. http://dx.doi.org/10.1371/journal.pone.0023033

[7] Koves, P.K., Biro, B., Voros, I., Takacs, T., Osztoics, E. and Strasser, R.J. (1998) Enhanced Activity of Microsymbiont-Alfalfa System Probed by the Fast Fluorescence Rise OJIP. In: Garab, P., Ed., Proceedings of the International Congress on Photosynthesis, Kluwer Academic Publishers, Dordrecht, 2765-2768.

[8] Percival, G.C. (2005) The Use of Chlorophyll Fluorescence to Identify Chemical and Environmental Stress in Leaf Tissue of Three Oak (Quercus) Species. Journal of Arboriculture, 31, 215-227.

[9] Georgieva, K. and Yordanov, I. (1993) Temperature Dependence of Chlorophyll Fluorescence Parameters of Pea Seedlings. Journal of Plant Physiology, 142, 151-155. http://dx.doi.org/10.1016/S0176-1617(11)80955-7

[10] Fujioka, S. and Yokota, T. (2003) Biosynthesis and Metabolism of Brassinosteroids. Annual Review Plant Biology, 5, 137-164. http://dx.doi.org/10.1146/annurev.arplant.54.031902.134921

[11] Sasse, J.M. (2003) Physiological Actions of Brassinosteroids: An Update. Journal of Plant Growth Regulation, 22, 276-288. http://dx.doi.org/10.1007/s00344-003-0062-3

[12] Feldmann, K. (2006) Steroid Regulation Improves Crop Yield. Nature Biotechnology, 24, 46-47. http://dx.doi.org/10.1038/nbt0106-46

[13] Li, J.M. and Chory, J. (1997) A Putative Leucine Rich Repeat Receptor Kinase Involved in Brassinosteroid Signal Transduction. Cell, 90, 929-38. http://dx.doi.org/10.1016/S0092-8674(00)80357-8

[14] Yamamuro, C., Ihara, Y., Wu, X., Noguchi, T., Fujioka, S., Takatsuto, S., Ashikari, M., Kitano, H. and Matsuoka, M. (2000) Loss of Function of a Rice Brassinosteroid Insensitive 1 Homolog Prevents Internode Elongation and Bending of the Lamina Joint. The Plant Cell, 12, 1591-1605. http://dx.doi.org/10.1105/tpc.12.9.1591 
[15] Montoya, T., Nomura, T., Farrar, K., Kaneta, T., Yokota, T. and Bishop, G.J. (2002) Cloning the Tomato Curl3 Gene Highlights the Putative Dual Role of the Leucine-Rich Repeat Receptor Kinase tBRI1/SR160 in Plant Steroid Hormone and Peptide Hormone Signaling. The Plant Cell, 14, 3163-3176. http://dx.doi.org/10.1105/tpc.006379

[16] Nomura, T., Bishop, G., Kaneta, T., Reid, J.B., Chory, J. and Yokota, T. (2003) The LKA Gene Is a BRASSINOSTEROID INSENSITIVE 1 Homolog of Pea. The Plant Journal, 36, 291-300. http://dx.doi.org/10.1046/j.1365-313X.2003.01863.x

[17] Sairam, R.K. (1994) Effect of Homobrasssinolide Application on Plant Metabolism and Grain Yield under Irrigated and Moisture-Stress Conditions of Two Wheat Cultivars. Journal of Plant Growth Regulation, 14, 173-181. http://dx.doi.org/10.1007/bf00025220

[18] Wang, B. and Zeng, G. (1993) Effect of Epibrassinolide on the Resistance of Rice Seedlings to Chilling Injury. Acta Phytophysiologica Sinica, 19, 38-42.

[19] Krishna, P. (2003) Brassinosteroid-Mediated Stress Resistance. Journal of Plant Growth Regulator, 22, $265-275$. http://dx.doi.org/10.1007/s00344-003-0058-z

[20] Kagale, S., Divi, U.K., Krochko, J.E., Keller, W.A. and Krishna, P. (2007) Brassinosteroid Confers Tolerance in Arabidopsis thaliana and Brassica napus to a Range of Abiotic Stresses. Planta, 225, 353-364. http://dx.doi.org/10.1007/s00425-006-0361-6

[21] Dhaubhadel, S., Browning, K.S., Gallie, D.R. and Krishna, P. (2002) Brassinosteroid Functions to Protect the Translational Machinery and Heat-Shock Protein Synthesis Following Thermal Stress. The Plant Journal, 29, 681-691. http://dx.doi.org/10.1046/j.1365-313X.2002.01257.x

[22] Dhaubhadel, S., Chaudhary, S., Dobinson, K.F. and Krishna, P. (1999) Treatment with 24-Epibrassinolide, a Brassinosteroid, Increases the Basic Thermotolerance of Brassica napus and Tomato Seedlings. Plant Molecular Biology, 40, 333-342. http://dx.doi.org/10.1023/A:1006283015582

[23] Nayyar, H. and Kaushal, S.K. (2002) Alleviation of Negative Effects of Water Stress in Two Contrasting Wheat Genotypes by Calcium and Abscisic acid. Biology of Plant, 45, 65-70. http://dx.doi.org/10.1023/A:1015132019686

[24] Rentel, M.C. and Knight, M.R. (2004) Oxidative Stress-Induced Calcium Signaling in Arabidopsis. Plant Physiology, 135, 1471-1479. http://dx.doi.org/10.1104/pp.104.042663

[25] Sanders, D., Pelloux, J., Brownlee, C. and Harper, J.F. (2002) Calcium at the Crossroads of Signaling. The Plant Cell, 14, S401-S417.

[26] Noctor, G. (2006) Metabolic Signalling in Defence and Stress: The Central Roles of Soluble Redox Couples. The Plant Cell and Environment, 29, 409-425. http://dx.doi.org/10.1111/j.1365-3040.2005.01476.x

[27] Kaya, C. and Higgs, D. (2002) Calcium Nitrate as a Remedy for Salt-Stressed Cucumber Plants. Journal Plant Nutrition, 25, 861-871. http://dx.doi.org/10.1081/PLN-120002965

[28] Jaleel, C.A., Manivannan, P., Sankar, B., Kishorekumar, A., Gopi, R., Somasundaram, R. and Panneerselvam, R. (2007) Water Deficit Stress Mitigation by Calcium Chloride in Catharanthus roseus: Effects on Oxidative Stress, Proline Metabolism and Indole Alkaloid Accumulation. Colloids Surfaces B: Biointerfaces, 60, 110-116. http://dx.doi.org/10.1016/j.colsurfb.2007.06.006

[29] Shao, H.B., Song, W.Y. and Chu, L.Y. (2008) Advances of Calcium Signals Involved in Plant Anti-Drought. Comptes Rendus Biologies, 331, 587-596. http://dx.doi.org/10.1016/j.crvi.2008.03.012

[30] Wang, C.Q. and Song, H. (2009) Calcium Protects Trifolium repens L. Seedlings against Cadmium Stress. The Plant Cell Reports, 28, 1341-1349. http://dx.doi.org/10.1007/s00299-009-0734-y

[31] Senthil-Kumar, M., Srikanthbabu, V., Mohan Raju, B., Ganeshkumar, Shivaprakash, N. and Udayakumar, M. (2003) Screening of Inbred Lines to Develop a Thermo-Tolerant Sunflower Hybrid Using the Temperature Induction Response (TIR) Technique: A Novel Approach by Exploiting Residual Variability. Journal of Experimental Botany, 54, 2569-2578. http://dx.doi.org/10.1093/jxb/erg278

[32] Hiscox, J.D. and Israelstam, G.F. (1979) A Method for Extraction of Chlorophyll from Leaf Tissue without Maceration. Canadian Journal of Botany, 57, 1332-1334. http://dx.doi.org/10.1139/b79-163

[33] Almeselmani, M., Deshmukh, P.S., Sairam, R.K., Kushwaha, S.R. and Singh, T.P. (2006) Protective Role of Antioxidant Enzymes under High Temperature Stress. Plant Science, 171, 382-388. http://dx.doi.org/10.1016/j.plantsci.2006.04.009

[34] Fisher, R.A. and Maurer, R. (1978) Drought Resistance in Wheat Cultivars. I. Grain Yield Response. Journal of Agricultural Research, 29, 898-907. http://dx.doi.org/10.1071/ar9780897

[35] Mamedov, M., Hayashi, H. and Murata, N. (1993) Effects of Glycinebetaine and Unsaturation of Membrane Lipids on Heat Stability of Photosynthetic Electron-Transport and Phosphorylation Relations in Synechocystis PCC6803. Biochimica et Biophysica Acta (BBA)-Bioenergetics, 1142, 1-5. http://dx.doi.org/10.1016/0005-2728(93)90077-S 
[36] Demmig-Adams, B., Adams, W.W., Barker, D.H., Logan, B.A., Verhoeven, A.S. and Bowling, D.R. (1996) Using Chlorophyll Fluorescence to Assess the Fraction of Absorbed Light Allocated to Thermal Dissipation of Excess Excitation. Physiologia Plantarum, 98, 253-264. http://dx.doi.org/10.1034/j.1399-3054.1996.980206.x

[37] Muller, P., Li, X.P. and Niyogi, K.K. (2001) Non-Photochemical Quenching. A Response to Excess Light Energy. Plant Physiology, 125, 1558-1566. http://dx.doi.org/10.1104/pp.125.4.1558

[38] Kramer, D.M., Johnson, G., Kiirats, O. and Edwards, G.E. (2004) New Fluorescence Parameters for the Determination of Q (A) Redox State and Excitation Energy Fluxes. Photosynthesis Research, 79, 209-218. http://dx.doi.org/10.1023/B:PRES.0000015391.99477.0d

[39] Anderson, J.M., Chow, W.S and Park, Y.I. (1995) The Grand Design of Photosynthesis: Acclimation of the Photosynthetic Apparatus to Environmental Cues. Photosynthesis Research, 46, 129-139. http://dx.doi.org/10.1007/BF00020423

[40] Schreiber, U. and Berry, J.A. (1977) Heat-Induced Changes of Chlorophyll Fluorescence in Intact Leaves Correlated with Damage of the Photosynthetic Apparatus. Planta, 136, 233-238. http://dx.doi.org/10.1007/BF00385990

[41] Srikanthbabu, V., Ganeshkumar, Krishnaprasad, B.T., Gopalakrishna, R., Savitha, M. and Udayakumar, M. (2002) Identification of Pea Genotypes with Enhanced Thermotolerance Using Temperature Induction Response Technique (TIR). Journal of Plant Physiology, 159, 535-545. http://dx.doi.org/10.1078/0176-1617-00650

[42] Natu, P.S., Savitha, M., Babu, S. and Udayakumar, M. (2007) Heat Shock Response of Wheat Cultivars Differing in Thermotolerance. Indian Journal of Plant Physiology, 12, 327-336.

[43] Mangelsen, E., Kilian, J., Harter, K., Jansson, C., Wanke, D. and Sundberg, E. (2011) Transcriptome Analysis of HighTemperature Stress in Developing Barley Caryopses: Early Stress Responses and Effects on Storage Compound Biosynthesis. Molecular Plant, 4, 97-115. http://dx.doi.org/10.1093/mp/ssq058

[44] Chauhan, H., Khurana, N., Nijhavan, A., Khurana, J.P. and Khurana, P. (2012) The Wheat Chloroplastic Small Heat Shock Protein (sHSP26) Is Involved in Seed Maturation and Germination and Imparts Tolerance to Heat Stress. Plant, Cell and Environment, 35, 1912-1931. http://dx.doi.org/10.1111/j.1365-3040.2012.02525.x

[45] Ruban, A. and Murchie, E.H. (2012) Assessing the Photoprotective Effectiveness of Non-Photochemical Chlorophyll Fluorescence Quenching: A New Approach. Biochimica et Biophysica Acta (BBA)-Bioenergetics, 1817, 977-982. http://dx.doi.org/10.1016/j.bbabio.2012.03.026

[46] Schreiber, U. and Bilger, W. (1987) Rapid Assessment of Stress Effects on Plant Leaves by Chlorophyll Fluoreecence Measurements. In: Tenhunen, J.D., Catarino, F.M., Lange, O.L. and Oechel, W.C., Eds., Plant Response to Stress: Functional Analysis in Mediterranean Ecosystems, Springer-Verlag, Berlin, 27-53. http://dx.doi.org/10.1007/978-3-642-70868-8 2

[47] Froux, F., Ducrey, M., Epron, D. and Dreyer, E. (2004) Seasonal Variations and Acclimation Potential of the Thermostability of Photochemistry in Four Mediterranean Conifers. Annals of Forest Science, 61, 235-241. http://dx.doi.org/10.1051/forest:2004016

[48] Weng, J.H. and Lai, M.F. (2005) Estimating Heat Tolerance among Plant Species by Two Chlorophyll Fluorescence Parameters. Photosynthetica, 43, 439-444. http://dx.doi.org/10.1007/s11099-005-0070-6

[49] Osmond, C.B. (1994) What Is Photoinhibition? Some Insights from Comparisons of Shade and Sun Plants. In: Baker, N.R. and Bowyer, J.R., Eds., Photoinhibition of Photosynthesis. From Molecular Mechanisms to the Field, BIOS Scientific Publishers, Oxford, 1-24.

[50] Blum, A. (1988) Plant Breeding for Stress Environments. CRC Press Inc., Boca Raton, 223.

[51] Quartacci, M.F., Pinzino, C., Sgherri, C.L.M., Vecchia, F.D. and Navari-Izzo, F. (2000) Growth in Excess Copper Induces Changes in the Lipid Composition and Fluidity of PSII-Enriched Membranes in Wheat. Physiologia Plantarum, 108, 87-93. http://dx.doi.org/10.1034/j.1399-3054.2000.108001087.x

[52] Falcone, D.L., Ogas, J.P. and Somerville, C.R. (2004) Regulation of Membrane Fatty Acid Composition by Temperature in Mutants of Arabidopsis with Alterations in Membrane Lipid Composition. BMC Plant Biology, 4, 17. http://dx.doi.org/10.1186/1471-2229-4-17

[53] Mittler, R. and Poulos, T.L. (2005) Ascorbate Peroxidase. In: Smirnoff, N., Ed., Antioxidants and Reactive Oxygen Species in Plants, Blackwell Publishing, Oxford, 87-100. http://dx.doi.org/10.1002/9780470988565.ch4

[54] Rosa, S.B., Caverzan, A., Teixeira, F.K., Lazzarotto, F., Silveira, J.A.G., Ferreira-Silva, S.L., Abreu-Neto, J., Margis, R. and Margis-Pinheiro, M. (2010) Cytosolic APX Knockdown Indicates an Ambiguous Redox Responses in Rice. Phytochemistry, 71, 548-558. http://dx.doi.org/10.1016/j.phytochem.2010.01.003

[55] Khripach, V., Zhabinskii, V. and De Groot, A. (2000) Twenty Years of Brassinosteroids: Steroidal Plant Hormones Warrant Better Crops for the XXI Century. Annals of Botany, 86, 441-447.

http://dx.doi.org/10.1006/anbo.2000.1227 
[56] Nakashita, H., Yasuda, M., Nitta, T., Asami, T., Fujioka, S., Arai, Y., Sekimata, K., Takatsuto, S., Yamaguchi, I. and Yoshida, S. (2003) Brassinosteroid Functions in a Broad Range of Disease Resistance in Tobacco and Rice. The Plant Journal, 33, 887-898. http://dx.doi.org/10.1046/j.1365-313X.2003.01675.x

[57] Bishop, G.J. and Koncz, C. (2002) Brassinosteroids and Plant Steroid Hormone Signaling. The Plant Cell, 14, S97S110.

[58] Mussig, C., Fischer, S. and Altmann, T. (2002) Brassinosteroid-Regulated Gene Expression. Plant Physiology, 129, 1241-1251. http://dx.doi.org/10.1104/pp.011003

[59] Cao, S.Q., Xu, Q.T., Cao, Y.J., Qian, K., An, K., Zhu, Y., Hu, B.Z., Zhao, H.F. and Kuai, B.K. (2005) Loss-of-Function Mutations in DET2 Gene Lead to an Enhanced Resistance to Oxidative Stress in Arabidopsis. Physiology Plant, 123, 57-66. http://dx.doi.org/10.1111/j.1399-3054.2004.00432.x

[60] Goda, H., Shimada, Y., Asami, T., Fujioka, S. and Yoshida, S. (2002) Microarray Analysis of Brassinosteroid-Regulated Genes in Arabidopsis. Plant Physiology, 130, 1319-1334. http://dx.doi.org/10.1104/pp.011254

[61] Gong, M., Van der Luit, A., Knight, M. and Trewavas, A. (1998) Heat-Shock Induces Changes in Intracellular Ca ${ }^{2+}$ Level in Tobacco Seedlings in Relation to Thermotolerance. Plant Physiology, 116, 429-437. http://dx.doi.org/10.1104/pp.116.1.429

[62] Liu, H.T., Gao, F., Cui, S.J., Han, J.L., Sun, D.Y. and Zhou, R.G. (2006) Primary Evidence for Involvement of IP in $_{3}$ Heat-Shock Signal Transduction in Arabidopsis. Cell Research, 16, 394-400. http://dx.doi.org/10.1038/sj.cr.7310051

[63] Saidi, Y., Finka, A., Muriset, M., Bromberg, Z., Weiss, Y.G., Maathuis, F.J., et al. (2009) The Heat Shock Response in Moss Plants is Regulated by Specific Calcium-Permeable Channels in the Plasma Membrane. The Plant Cell, 21, 2829-2843. http://dx.doi.org/10.1105/tpc.108.065318

[64] Wu, H.C. and Jinn, T.L. (2010) Ethylesterase Activity and Cytosolic $\mathrm{Ca}^{2+}$ Oscillation Are Crucial for Plant Thermotolerance. Plant Signaling Behaviour, 5, 1252-1256. http://dx.doi.org/10.4161/psb.5.10.12607

[65] Zhang, W., Zhou, R.G., Gao, Y.J., Zheng, S.Z., Xu, P., Zhang, S.Q., et al. (2009) Molecular and Genetic Evidence for the Key Role of $\mathrm{AtCaM}_{3}$ in Heat-Shock Signal Transduction in Arabidopsis. Plant Physiology, 149, 1773-1784. http://dx.doi.org/10.1104/pp.108.133744 

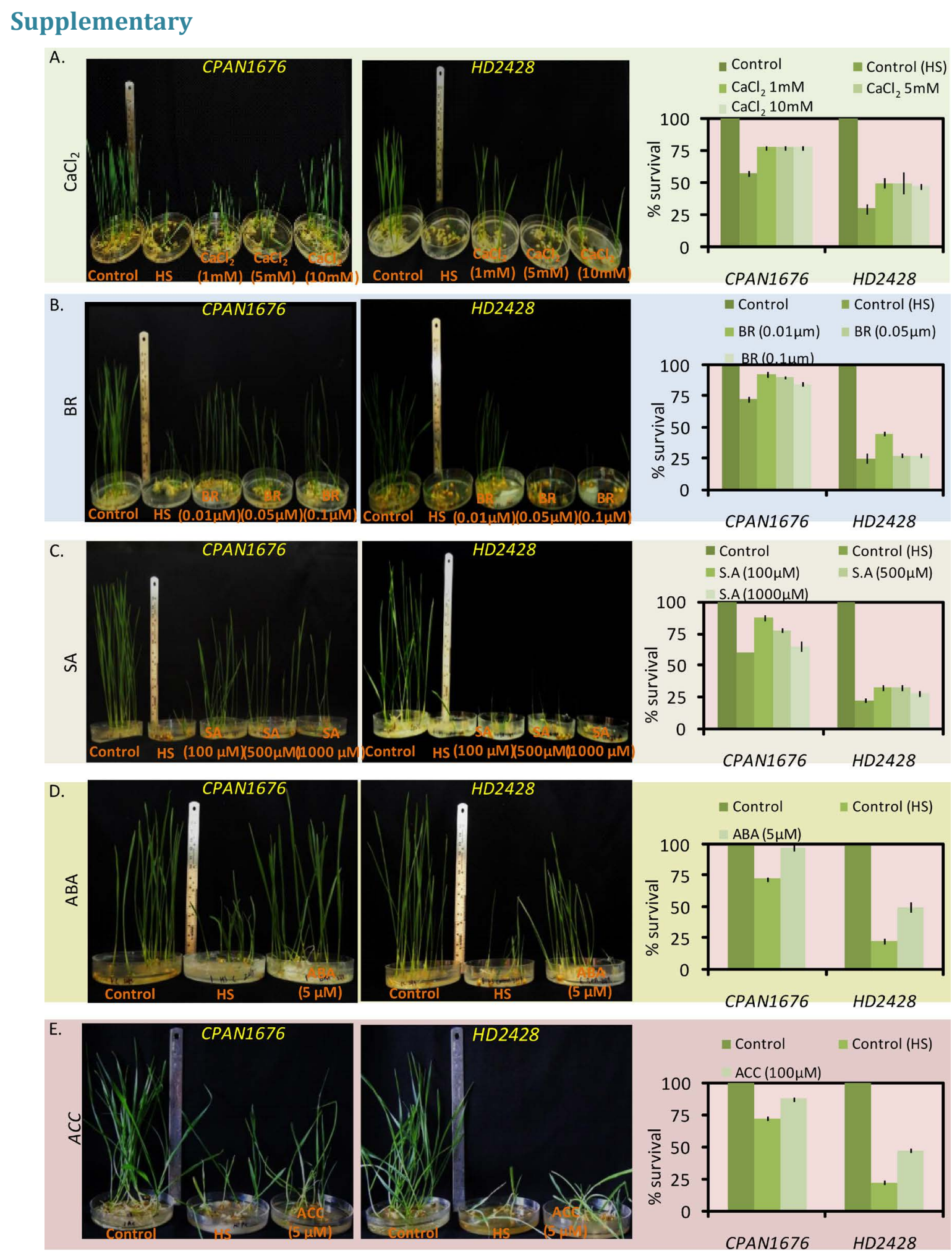

Figure S1. Effect of different concentration of ameliorating compunds. (a) Calcium chloride $\left(\mathrm{CaCl}_{2}\right)$; (b) Brassinosteroid (BR); (c) Salicylic acid (SA); (d) Abcissic acid (ABA); (e) 1-aminocyclopropane-1-carboxylic acid (ACC), on percentage survival in response to heating in different wheat cultivars (CPAN1676 and HD2428). Plants were imbibed for $12 \mathrm{~h}$ in different concentrations of of these compounds prior to lethal temperature stress of $51^{\circ} \mathrm{C}$ for $3 \mathrm{~h}$. Graphs indicate percentage survival 10 days after the temperature treatment. 

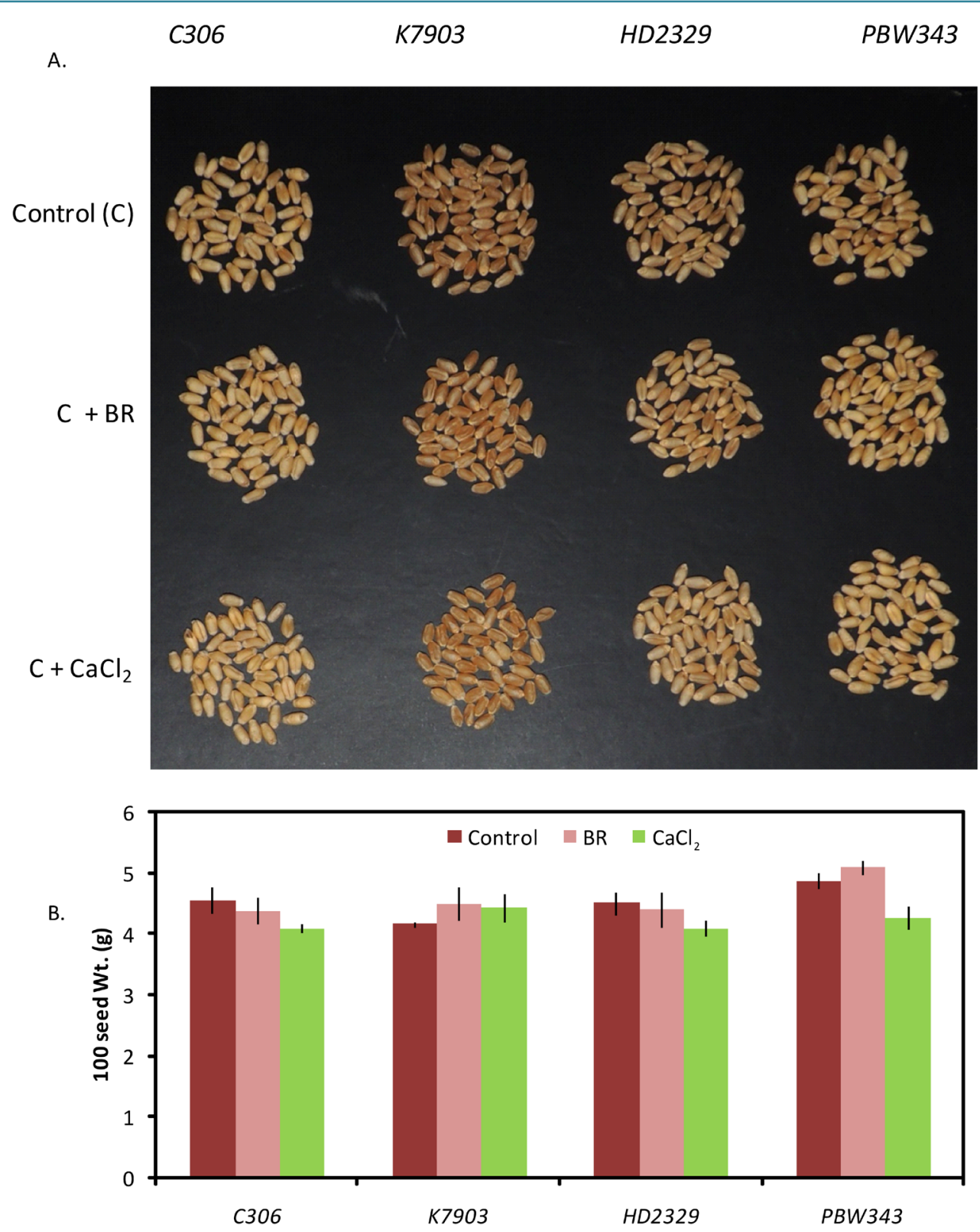

Figure S2. A comparative graph of control and ameliorating agent treated cultivars. Vertical lines on top of bars indicate standard error of means. 